\title{
Problemática contable de las provisiones, cambios en criterios contables, errores, estimaciones y hechos posteriores al cierre
}

\author{
Raquel Flórez López \\ raquel.florez@unileon.es \\ Universidad de León \\ Fac. de Ciencias Económicas y Empresariales \\ Campus de Vegazana, $\mathrm{s} / \mathrm{n}$ \\ 24071 León (España)
}

\section{LAS PROVISIONES Y CONTINGENCIAS}

1.1. Razón de ser, concepto y reconocimiento contable

Las empresas se desenvuelven en un ambiente de incertidumbre lo que motiva que, junto con hechos económicos ciertos y totalmente determinados (cuyo registro contable no plantea problemas), se den otros en los que, por presentar un cierto grado de incertidumbre, se dificulte su contabilización. La necesidad de contar con la mejor información posible sobre la situación de la empresa en el momento de elaboración de las Cuentas Anuales lleva a que no se pueda esperar a que todos los hechos que le afecten se concreten, sino que en muchas ocasiones resulta necesario establecer supuestos y efectuar estimaciones sobre algunas operaciones sujetas a incertidumbre en la fecha de cierre del ejercicio. De esta forma, se consigue el cumplimiento del principio 
contable del devengo (así como del antiguo principio de correlación de ingresos gastos) y se facilita la consecución del objetivo de la imagen fiel que debe presidir la formulación de la información financiera.

Las provisiones recogidas en el NPGC vienen a cubrir esta necesidad de contabilizar operaciones inciertas al cierre del ejercicio, pero que pueden afectar de forma significativa a la operativa futura de la entidad. En su norma de valoración $5^{a}$ referida a los pasivos financieros, el NPGC (versión normal y PYME) incluye dentro de los mismos a las denominadas "provisiones" y "contingencias", definidas como sigue:

- Provisiones: Pasivos que cumpliendo la definición de pasivos y los criterios de registro o reconocimiento contable contenidos en el Marco Conceptual de la Contabilidad, resulten indeterminados respecto a su importe o la fecha en que se cancelarán.

- Contingencias: Importes no reconocidos contablemente como pasivos por no cumplir los requisitos establecidos en el marco conceptual de la contabilidad; bien representan obligaciones probables pero no presentes en la empresa; obligaciones presentes pero su importe no puede estimarse con suficiente fiabilidad; obligaciones presentes pero que es posible que no originen salida de recursos.

Si bien las provisiones se contabilizan como pasivos en las cuentas habilitadas para ello, por lo que afectan a todas las Cuentas Anuales de la empresa, las contingencias no son objeto de registro, informándose únicamente en la Memoria de su existencia y características. A pesar de las importantísimas implicaciones contables de la distinción entre ambos términos, en la práctica la distinción entre unas y otras no resulta inmediata, tal como se recoge en el Ejemplo 1, quedando a juicio del experto contable su correcta caracterización.

Al estar definidas las provisiones como "pasivos"1 según el Marco Conceptual del NPGC, quedan fuera de este concepto las provisiones por depreciación del valor de los activos contempladas en el PGC de 1990 (las denominadas "provisiones de activo"), que pasan a denominarse

1 El Marco Conceptual del NPGC define los pasivos como obligaciones actuales surgidas como consecuencia de sucesos pasados, para cuya extinción la empresa espera desprenderse de recursos que puedan producir beneficios o rendimientos económicos en el futuro (Primera parte NPGC, apartado $4^{\circ}$ ). 
"deterioros de valor de los activos" y a regirse por las normas de valoración específicas de los elementos patrimoniales correspondientes. De esta forma, la definición de provisión contemplada en la norma $5^{a}$ del NPGC se circunscribe exclusivamente a las provisiones para riesgos y gastos incluidas en el PGC de 1990.

Por último, las provisiones se diferencian de otros pasivos, como los acreedores comerciales y otras obligaciones devengadas que son objeto de estimación, por la existencia de incertidumbre acerca del momento del vencimiento o de la cuantía de los desembolsos futuros necesarios para proceder a su cancelación.

Figura 1. Reconocimiento contable de las provisiones y contingencias

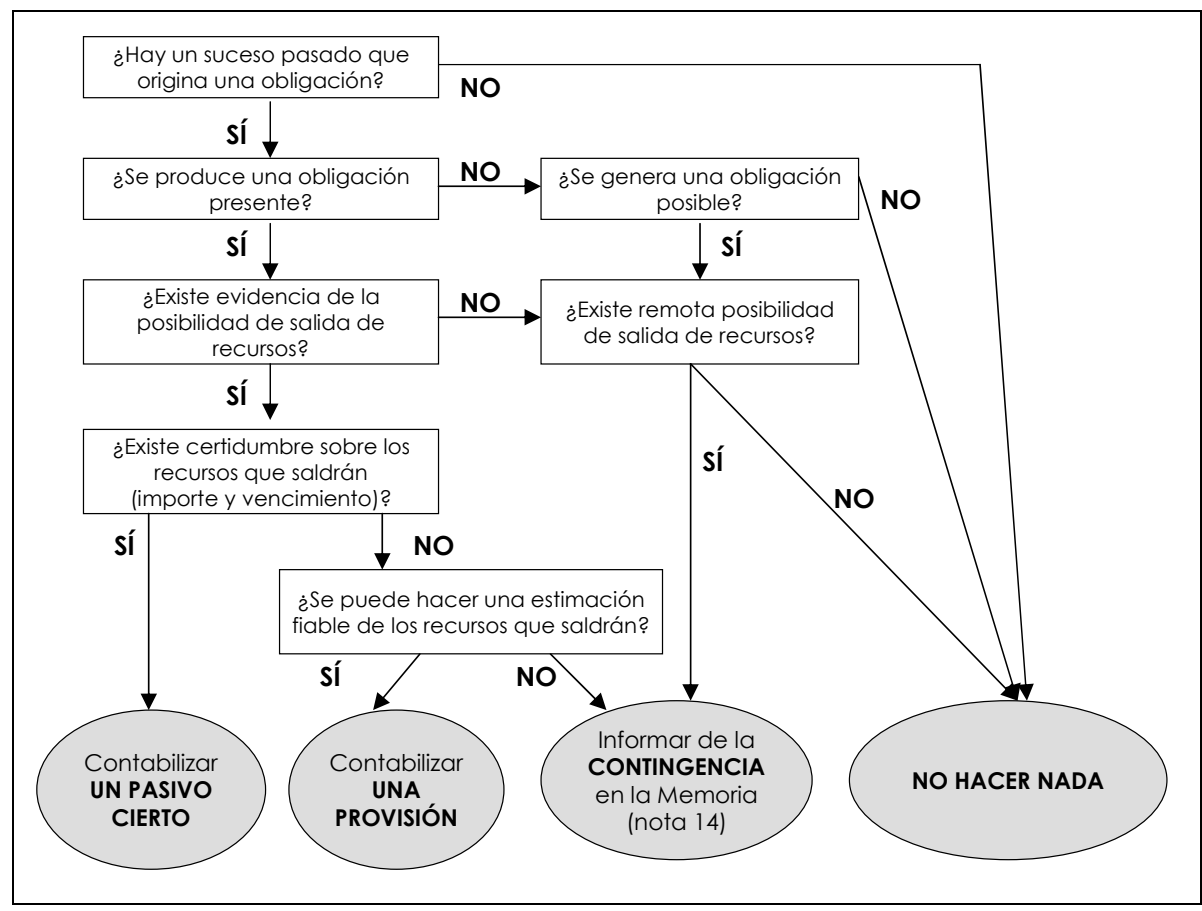

Fuente: Elaboración propia.

Según la norma de valoración $n^{\circ} 15$ (respectivamente $n^{\circ} 17$ para PYMEs), las obligaciones que originan el reconocimiento contable de una provisión pueden ser de dos tipos:

1. Legales, cuando así lo establezca la legislación, las condiciones contractuales (implícitas o explícitas) u otra causa de tipo legal. 
2. Implícitas o tácitas, derivadas de actuaciones de la empresa que creen expectativas frente a terceros de asunción de una obligación por parte de aquélla, debido principalmente a patrones establecidos de comportamiento en el pasado, a políticas empresariales que sean de dominio público o a una declaración efectuada de forma suficientemente concreta, se haya puesto de manifiesto ante terceros que está dispuesta a aceptar cierto tipo de responsabilidades.

La Figura 1 resume las distintas circunstancias que pueden dar lugar al reconocimiento contable de un pasivo cierto, una provisión o una contingencia, en su caso.

\section{Ejemplo $n^{0}$ 1.-}

Identificar razonadamente, de acuerdo con las normas de valoración del NPGC, si la correspondiente empresa debería reconocer: (a) un pasivo cierto; (b) una provisión; (c) una contingencia.

Caso 1.- Una determinada fábrica se plantea la colocación de un filtro de humos que mejore las condiciones laborales futuras, estimándose su importe en 15.000€. ¿Tiene la fábrica una obligación presente como consecuencia de sucesos pasados? ¿Debería reconocer una provisión?

Caso 2.- Una empresa ocasiona un daño medioambiental en la zona en la que está ubicada. estando vigente a la fecha de elaboración del Balance (31-12-08) una ley medioambiental que obliga a la empresa a sanear estos daños (por importe de 24.000€) así como una multa medioambiental por otros $5.000 €$ adicionales, si bien los desembolsos no habrán realizarse hasta Junio de 2009.

Caso 3.- Una empresa ocasiona un daño medioambiental en la zona en la que está ubicada, debido al desarrollo normal de su actividad. Un técnico especializado estima el importe del daño en 20.000€, pero a 31-12-08, fecha de elaboración del Balance, no existe ninguna ley que obligue a la empresa a sanear estos daños, por lo que no son reparados. Ahora bien, se sabe que hay una ley en proceso de redacción, cuya aprobación es muy probable que tenga lugar durante el primer trimestre de 2009, que obligará a la empresa a sanear los daños ocasionados con efectos retroactivos.

Caso 4.- Una empresa realiza su actividad en un país donde no existe legislación medioambiental. Debido a la realización de sus actividades, la empresa ocasiona daños medioambientales en el año 2008 por importe de $20.000 €$, responsabilizándose de la reparación de los mismos a lo largo del ejercicio 2009. Esta empresa habitualmente cumple los compromisos adquiridos.

Caso 5.- Una empresa tiene una fábrica en un país que carece de legislación medioambiental, ni la tiene prevista. En el año 2008, la fábrica ocasiona la contaminación de unos terrenos, como consecuencia de los vertidos realizados. El daño causado es evaluado por el personal interno de la empresa en 20.000€. Aunque no es habitual que la empresa repare los daños causados por este motivo, en esta ocasión la dirección acuerda su reparación, si bien esta decisión aún no se ha comunicado de forma explícita a los interesados en el momento de elaborar el Balance de Situación. 


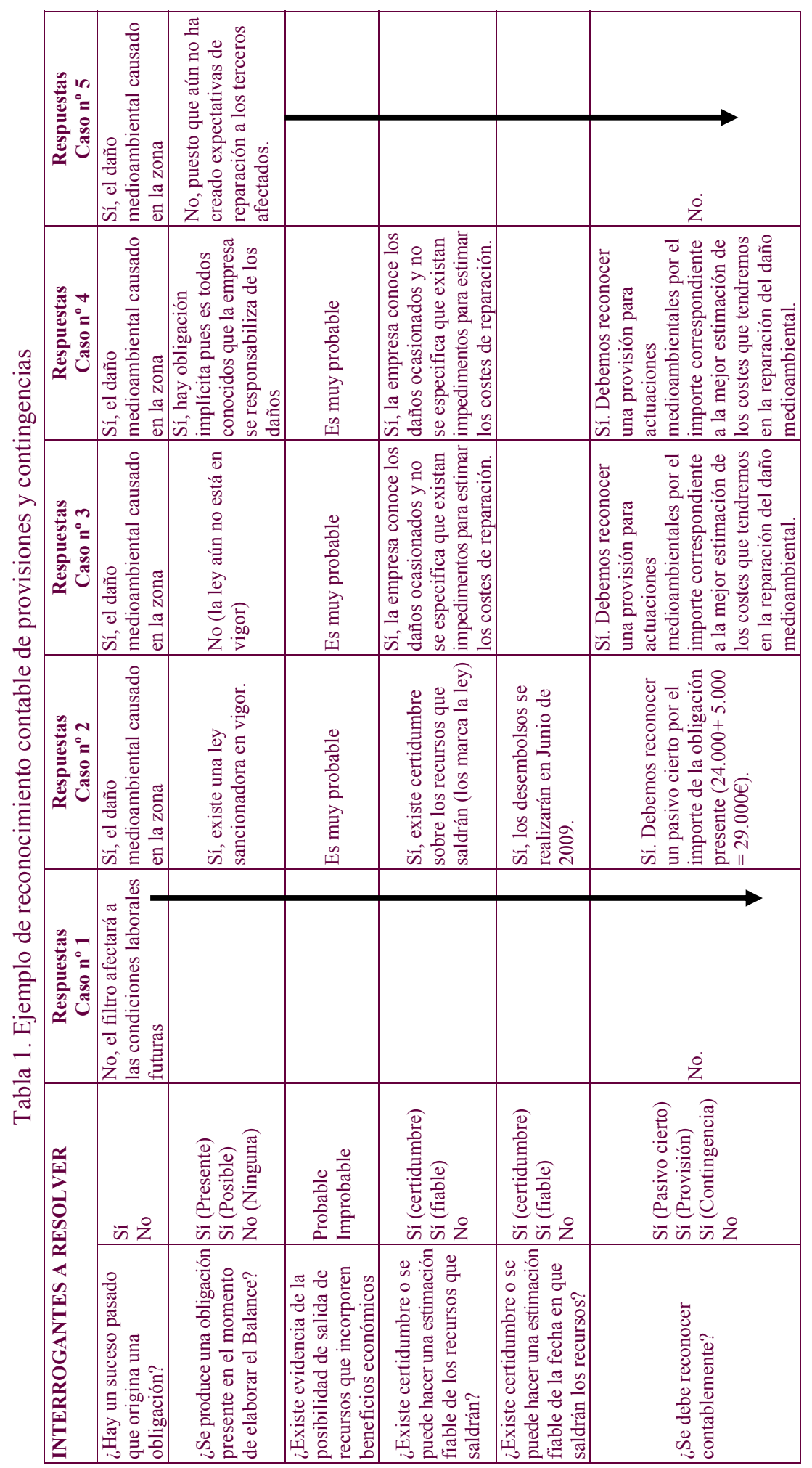




\subsection{Registro contable}

Para el reconocimiento contable de las distintas provisiones, el NPGC preve utilizar dos categorías principales de cuentas: el subgrupo "14. Provisiones" y la cuenta "52. Provisiones a corto plazo".

(14) Provisiones. Las cuentas incluidas en este subgrupo hacen referencia a la generalidad de las provisiones cuya cancelación se prevea a largo plazo (más de un año), por lo que figurarán en el pasivo no corriente del Balance de Situación ${ }^{2}$ :

140. Provisión por retribuciones a largo plazo al personal(*). Recoge las obligaciones con el personal de la empresa, legales, contractuales, o implícitas, de cuantía o vencimiento incierto, excluyendo las derivadas de reestructuraciones (cuenta 146) y aquéllas cuyo pago se instrumente mediante instrumentos de patrimonio (cuenta 147); p.e. retribuciones a largo lazo de prestación definida (fondos de pensiones internos), prestaciones por incapacidad laboral, indemnizaciones por despido, etc.

141. Provisión para impuestos. Recoge el importe estimado de deudas con la Administración Tributaria de cuantía o vencimiento incierto; p.e. tributos liquidados sujetos a comprobación posterior, sanciones en proceso de recurso, etc.

142. Provisión para otras responsabilidades. Obligaciones de cuantía indeterminada no incluidas en ninguna de las restantes cuentas del subgrupo 14; p.e. obligaciones procedentes de litigios en curso, indemnizaciones derivadas de avales o garantías a cargo de la empresa, etc.

143. Provisión por desmantelamiento, retiro o rehabilitación del inmovilizado(*). Importe estimado de los costes de desmantelamiento o retiro del inmovilizado, así como la rehabilitación del lugar en el que se asienta. Estas obligaciones pueden surgir en el momento de adquirir el inmovilizado o como consecuencia de su uso.

\footnotetext{
De esta forma se soluciona uno de los problemas que presenta el PGC'90, que no incluye las provisiones para riesgos y gastos dentro de los recursos propios ni en el pasivo exigible del Balance, sino en una masa intermedia específica e indefinida, lo que ha dificultado la realización de análisis financieros de calidad. analizada en el apartado 1.4

Las cuentas marcadas con asterisco $\left(^{*}\right)$ presentan una problemática particular
} 
145. Provisión para actuaciones medioambientales. Obligaciones de la empresa de cuantía o vencimiento indeterminado, destinadas a prevenir o reparar daños medioambientales, excluyendo las que deban ser recogidas en la cuenta 143.

146. Provisión para reestructuraciones $\left({ }^{*}\right)$. Importe estimado de los costes que surjan directamente de una reestructuración empresarial.

147. Provisión por transacciones con pagos basados en instrumentos de patrimonio. Obligaciones de la empresa cuya liquidación se prevea realizar por un importe efectivo que depende del valor incierto de instrumentos de patrimonio. La problemática de esta provisión queda fuera del ámbito de este artículo dado que su valoración se aproxima a la de los instrumentos financieros, estando regulada en la Norma de Registro y Valoración $n^{\circ} 17$ "Transacciones con pagos basados en instrumentos de patrimonio".

A diferencia del anterior PGC'90, el NPGC destina una cuenta específica para registrar la parte de las provisiones cuya cancelación se prevea en el corto plazo (igual o inferior a un año), que deberá figurar en el Pasivo Corriente del Balance de Situación. Dado que la cuenta "529. Provisiones a corto plazo" surge por la reclasificación de las provisiones previamente descritas, las distintas subcuentas que la integran incorporan los mismos conceptos que el subgrupo 14 .

Las provisiones se reconocerán al cierre del ejercicio por el importe estimado del devengo anual, utilizando como contrapartida las cuentas de gasto correspondientes a los conceptos que las generen, según su naturaleza, y de acuerdo con las normas de valoración comentadas a continuación. Las provisiones se utilizarán únicamente para los fines para los que se dotaron. En el caso de que la salida de recursos destinada a cancelar la obligación deje de ser probable, se deberá revertir la provisión utilizando la cuenta "795. Excesos de provisiones"; en particular, si al hacer la revisión de la provisión se estima una probabilidad alta de la no salida de recursos que incorporen beneficios económicos, se deberá cancelar la provisión.

Dentro del resultado de explotación de la Cuenta de Pérdidas y Ganancias se recogerá el importe dotado en el ejercicio, según la naturaleza del gasto correspondiente, así como los excesos de provisiones. 
Estos conceptos no aparecen en el Estado de Cambios en el Patrimonio Neto, si bien la variación de las provisiones supone un ajuste al resultado dentro del Estado de Flujos de Efectivo de las operaciones de explotación.

Aunque el NPGC elimina del concepto de provisión las dotaciones por pérdidas reversibles en el valor de los activos, mantiene la cuenta "499. Provisión por operaciones comerciales" para el reconocimiento de coberturas derivadas del tráfico comercial, como gastos por devoluciones de ventas, garantías de reparación, revisiones y otros conceptos análogos. Esta cuenta debe figurar en el pasivo no corriente del Balance si su vencimiento supera el plazo de un año, incluyendo como novedad una subcuenta destinada a recoger las obligaciones correspondientes a contratos onerosos:

4994. Provisión por contratos onerosos.

4999. Provisión para otras operaciones comerciales.

Sorprendentemente ${ }^{3}$, el funcionamiento y terminología contable de la cuenta 499 es idéntico al previsto en el PGC' 90 , abonándose al cierre del ejercicio por el importe de la estimación realizada con cargo a la cuenta "695. Dotación a la provisión por operaciones comerciales", y cargándose por la dotación efectuada el año anterior con abono a la cuenta "7954. Exceso de provisión por operaciones comerciales".

Ejemplo n ${ }^{0}$ 2.-

El centro comercial ESPACIO 1000 utiliza, como política de ventas, el lema "si no le gusta lo que ha comprado le devolvemos lo pagado". A 31-12-08, la entidad estima, sobre la base de unas estadísticas elaboradas y consideradas fiables, que de las ventas con garantías vivas, por un total de 600.000 euros, es probable que un 5\% de sus clientes devuelvan los productos adquiridos. A finales del año 2007 la empresa estimó y contabilizó una devoluciones previstas para el año 2008 de $20.000 €$.

Solución.-

A finales del año 2008 existe una obligación implícita presente debido a una política empresarial de dominio público, siendo probable la salida de recursos y se puede estimar de forma fiable el importe de la provisión: $5 \% \times 600.000=30.000 €$.

3 Esta es la única ocasión en que el NPGC incluye la expresión "dotación" para designar el reconocimiento contable de una provisión. 
31-12-08:

$30.000,0 0 \longdiv { 6 9 5 \text { Dotación a la provisión por } }$ a operaciones comerciales

4999 Provisión para otras

operaciones comerciales

$30.000,00$

Por su parte, debe eliminarse la provisión reconocida en el ejercicio anterior, dado que las obligaciones correspondientes ya fueron canceladas a lo largo del año 2008:

31-12-08:

\begin{aligned} & \cline { 2 - 2 } $20.000,00 \begin{array}{c}499 \text { Provisión para otras } \\ \text { operaciones comerciales }\end{array} \\ &$\hline\end{aligned}

7954 Exceso de provisión por operaciones comerciales $20.000,00$

Por último, el NPGC incorpora la cuenta "585. Provisiones" para el registro de las provisiones relacionadas con activos no corrientes mantenidos para la venta, esto es, aquellos elementos de inmovilizado cuya recuperación se espera realizar fundamentalmente a través de su enajenación, en lugar de por su uso continuado. Dado que esta cuenta surge por la reclasificación de los activos no corrientes como mantenidos para la venta, su funcionamiento contable es idéntico al descrito para el subgrupo 14.

Si se comparan las cuentas previstas en el NPGC para el registro contable de las provisiones con las recogidas en el PGC'90 puede observarse que:

1) Con pequeños cambios de denominación, se mantienen las cuentas "140. Provisión por retribuciones a largo plazo al personal", "141. Provisión para impuestos", "142. Provisión para otras responsabilidades" y "499. Provisión por operaciones comerciales" ya previstas en la normativa anterior.

2) Se incorporan cuentas adicionales destinadas a recoger nuevos conceptos provisionables, como "143. Provisión por desmantelamiento, retiro o rehabilitación del inmovilizado", "145. Provisión para actuaciones medioambientales", "146. Provisión para reestructuraciones", "147. Provisión por transacciones con pagos basados en instrumentos de patrimonio", "529. Provisiones a corto plazo", "585. Provisiones".

3) Se han suprimido dos conceptos de provisiones recogidos en el PGC'90:

- "Provisión para grandes reparaciones": Su eliminación se debe a que carece de las características requeridas para ser reconocida como pasivo. Esto puede afectar sustancialmente a empresas 
con grandes inversiones en inmovilizado (p.e. navieras o compañías aéreas), por lo que la Norma de Registro y Valoración $n^{\circ} 3$ recoge como solución alternativa que, siempre que la gran reparación pueda considerarse como una sustitución o una mejora, su coste estimado se amortizará de forma distinta a la del resto del elemento durante el periodo que medie hasta la gran reparación (véase el apartado 1.4).

- "Fondo de reversión": Su eliminación se debe al nuevo tratamiento contable de los activos sujetos a reversión (p.e. explotación de autopistas de peaje o puertos deportivos), que pasan a amortizarse durante su vida úti ${ }^{4}$, lo que hace innecesaria la creación de un fondo de reversión adicional.

\subsection{Valoración inicial y posterior}

A partir de la mejor información disponible en cada momento, las provisiones se valorarán, en la fecha de cierre de cada ejercicio, de acuerdo con las siguientes normas ${ }^{5}$ :

- Si su vencimiento se estima que se producirá en un plazo > 1 año: Por el valor actual de la mejor estimación posible de los importes necesarios para cancelarlas o para transferir a un tercero las obligaciones derivadas de ellas. Asimismo, se registrarán como gastos financieros los ajustes procedentes de la actualización de los importes según se vayan devengando.

- Si su vencimiento se estima que se producirá en un plazo $\leq 1$ año: Por el importe de la mejor estimación, sin llevar a cabo ningún tipo de descuento por actualización.

De las norma previas se derivan dos interrogantes importantes a resolver para la valoración de las provisiones: (a) ¿cómo se determina "la mejor estimación posible" del importe de una provisión?; y (b) ¿cómo

$4 \quad$ La vida útil es el periodo durante el cual la empresa espera utilizar el activo amortizable o el número de unidades de producción que espera obtener del mismo; en particular, en el caso de activos sometidos a reversión, su vida útil es el periodo concesional cuando éste sea inferior a la vida económica del activo (NPGC, Marco Conceptual, criterios de registro o reconocimiento contable de los elementos de las cuentas anuales, norma 10).

5 La valoración de las provisiones se hará siempre antes de impuestos. 
se calcula el valor actual para las provisiones con vencimiento superior a un año?.

1.3.1. Cálculo de la mejor estimación posible del importe de una provisión

El concepto de "mejor estimación posible" puede definirse como el importe evaluado de forma racional que la empresa tendría que pagar para cancelar la obligación o transferirla a un tercero, a la fecha de elaboración del Balance. La empresa debe utilizar toda la evidencia posible para realizar esta estimación, incluyendo el juicio de la gerencia, la experiencia que tenga de operaciones similares, e incluso los sucesos ocurridos con posterioridad a la fecha de cierre de los estados financieros.

Además, la empresa debe considerar las características particulares de la provisión objeto de estimación (véase el Ejemplo $n^{\circ} 2$ ); si la provisión se refiere a una población importante de casos individuales, la estimación puede fundamentarse en el método estadístico del "valor esperado", que consiste en calcular el promedio de todos los desenlaces posibles, ponderados por su probabilidad asociada; si la provisión se refiere a una obligación aislada, la mejor estimación corresponde al desenlace individual más probable ajustada por otros desenlaces posibles si éstos tienen un coste diferente.

Si bien el PGC'90 no regulaba expresamente los reembolsos relacionados con las provisiones, el NPGC indica que los derechos de cobro a percibir de terceros en el momento de liquidar la provisión no minoran el importe de la obligación contraída, sin perjuicio de reconocer un activo siempre que no existan dudas razonables sobre su percepción y su importe no sea superior al de la provisión. Sólo si existe un vínculo legal o contractual, por el cual la empresa haya exteriorizado parte del riesgo asumido, y en virtud del cual la empresa no esté obligada a responder de una obligación, se tendrá en cuenta para estimar el importe de la provisión (p.e.: una empresa obligada a constituir un fondo de pensiones para sus empleados, si contractualmente tiene la facultad de exteriorizar el mismo acudiendo a una entidad financiera, pero manteniendo responsabilidad subsidiaria hasta que se produzca el pago efectivo de las pensiones, deberá reflejar dicha responsabilidad mediante una provisión que evaluará teniendo en cuenta todas las circunstancias de la externalización que haya contratado). 
Por último, la empresa deberá considerar los siguientes factores adicionales al estimar el importe de la provisión:

1) Todos los riesgos e incertidumbres que rodean a la provisión, entendiendo por riesgo la variación en los desenlaces posibles, de los que se proporcionará información suficiente en la Memoria. A diferencia del PGC'90, la existencia de incertidumbre no justifica el reconocimiento de provisiones excesivas o la sobrevaloración deliberada de los pasivos, con independencia de que se utilice la prudencia en la valoración de la provisión.

2) Sucesos futuros que pueden afectar al importe necesario para cancelar la obligación, siempre que exista suficiente evidencia objetiva de que pueden acontecer (p.e., evolución prevista de la tecnología o cambios anunciados en la legislación).

3) Resultados esperados en la venta de activos, que no deben considerarse al evaluar el importe de la provisión, incluso aunque tal enajenación esté estrechamente ligada al suceso que ha provocado la provisión (p.e., el resultado por la venta de maquinaria de una fábrica no se considerará al estimar el importe de la provisión por costes medioambientales incurridos al utilizar dicha máquina).

\section{Ejemplo n ${ }^{\circ}$ 3.-}

Indicar el importe correspondiente a la mejor estimación de la provisión asociada a los siguientes casos particulares. Contabilizar la operación.

Caso 1.- La empresa "LILA" vende un determinado producto con garantía de reparación hasta un año, por los defectos de fabricación que pudieran presentarse. Según las estimaciones realizadas por la empresa, en el año 2009 se producirán gastos de reparación si se producen defectos de fabricación en todos los productos vendidos, por valor de (a) 1.000 .000 en el caso de defectos menores; (b) 4.000.000 en el caso de defectos importantes. La experiencia de la empresa en el pasado, junto con las expectativas futuras, indican que para el año próximo no se producirán defectos en el $75 \%$ de los artículos, se detectarán defectos menores en el $20 \%$ y en el restante $5 \%$ aparecerán defectos importantes.

\section{Solución.-}

Se trata de una población importante de casos individuales y se conocen las probabilidades asociadas a los distintos escenarios, por lo que puede aplicarse el método estadístico del valor esperado del coste de las reparaciones.

$$
(75 \% \times 0)+(20 \% \times 1.000 .000)+(5 \% \times 4.000 .000)=400.000 €
$$


31-12-08:

$\begin{array}{cccc}\begin{array}{c}\text { 695 Dotación a la provisión por } \\ \text { operaciones comerciales }\end{array} & \begin{array}{c}4999 \text { Provisión para otras } \\ \text { operaciones comerciales }\end{array} & 400.000,00\end{array}$

Caso 2.- Una empresa constructora ha de reparar un defecto importante en una planta industrial que ha realizado a uno de sus clientes. La empresa estima que lo más probable es que la reparación se consiga realizar en el primer intento, que supondrá un coste de 30.000€. Ahora bien, se considera que hay probabilidades significativas de que la reparación se consiga realizar en un segundo o tercer intento.

\section{Solución.-}

En este caso, relativo a una obligación aislada, la provisión se dotará por un importe superior a $30.000 €$, pues la probabilidad de que la reparación se produzca en un segundo o tercer intento es importante, lo que incrementará el coste total.

Caso 3.- La empresa "Reformas Pincho, S.A." (REPISA) se dedica a realizar reformas inmobiliarias. En el año 2008, su cliente "Elías Decoración, S.A." le demanda por el derrumbe de una techumbre y anexos de una obra realizada por REPISA durante el año 2007. A 31-12-08, los abogados de REPISA informan a ésta que es muy probable que se pierda el juicio, cuya sentencia se estima que será firme en el año 2009, habiendo realizado una estimación acerca de los importes relativos a la futura indemnización a pagar, así como sus probabilidades asociadas (entre paréntesis): $5.000 €(5 \%) ; 25.000 €$ (30\%); 60.000€ (50\%); $80.000 €(10 \%) ; 150.000 €(5 \%)$.

\section{Solución.-}

Se trata de una obligación aislada para la que se conoce la probabilidad asociada a los distintos desenlaces posibles, por lo que resulta posible aplicar el método estadístico del valor esperado:

$$
(5 \% \times 5.000)+(30 \% \times 25.000)+(50 \% \times 60.000)+(10 \% \times 80.000)+(5 \% \times 150.000)=53.250 €
$$

$53.250,0 0 \longdiv { 6 7 8 \text { Gastos excepcionales } }$ a

Caso 4.- La empresa "ALFA" se dedica a la venta de lavadoras, ofreciendo una garantía de reparación o devolución durante un año. Asimismo, tiene contratado con una entidad de seguros la cobertura del $50 \%$ de las indemnizaciones o reparaciones efectuadas como consecuencia de estas garantías. A la fecha de cierre del año 2008, la mejor estimación posible sobre las garantías contraídas por la empresa, calculada estadísticamente a partir de las garantías ejecutadas en años anteriores, asciende a $8.000 €$.

\section{Solución.-}

El derecho de cobro a recibir de un tercero no minora el importe de la provisión, puesto que no se ha externalizado el riesgo respecto a los terceros (es decir, la aseguradora no pagará directamente a los terceros sino a la empresa "ALFA"), aunque sí dará lugar a la contabilización de un activo por el importe estimado de la compensación. 


\section{1-12-08:}

$\begin{array}{cc}4.000,00 & \begin{array}{c}695 \text { Dotación a la provisión por } \\ \text { operaciones comerciales }\end{array} \\ 4.000,00 \quad 440 \text { Deudores }\end{array}$

1.3.2. Cálculo del valor actual para provisiones con vencimiento superior al año

A diferencia del PGC'90, que no considera el efecto financiero de los activos y pasivos, el NPGC exige que, si la obligación provisionada tiene una fecha de vencimiento que supera el año, se registre por el valor actual de los desembolsos de efectivo futuros necesarios para cancelarla, utilizando un tipo de descuento adecuado.

Para calcular el valor actual en el momento presente $(t=0)$ se aplicará la fórmula general del descuento compuesto:

$$
\text { Valor actual }_{0}=\sum_{j=1}^{N} \frac{\text { Desembolso }_{\mathrm{j}}}{(1+i)^{\mathrm{j}}}
$$

siendo $i$ el tipo de descuento a aplicar, que según el NPGC será el correspondiente al tipo de interés libre de riesgo ajustado, en su caso, por una prima de riesgo específica según el sector de actividades de la empresa. Esta definición, excesivamente vaga y abierta, plantea dificultades para su aplicación, existiendo diversas propuestas sobre el tipo de descuento a utilizar, como el tipo de interés legal del dinero (proporcionado por el Banco de España), o el tipo de interés de la deuda pública cuyo plazo coincida con el vencimiento de la provisión (letras del Tesoro a 3, 6 ó 12 meses, bonos del Estado a 3 ó 5 años). En la práctica, será el gestor de la empresa el que decida el tipo de descuento más adecuado en función de las características del hecho contable y de la entidad analizada.

Al final de cada ejercicio la empresa deberá recalcular el valor actual de todas sus provisiones, contabilizando el efecto financiero generado durante el ejercicio mediante la cuenta "660. Gastos financieros por actualización de provisiones", incluida en el resultado de explotación de la Cuenta de Pérdidas y Ganancias.

\section{Ejemplo $n^{0}$ 4.-}

Indicar el importe correspondiente a la provisión asociada a los siguientes casos particulares. Contabilizar la operación. 
Caso 1.- La empresa "PRE, S.A.", dedicada a la fabricación y prensado de planchas de aluminio, es denunciada por uno de sus clientes a lo largo del año 2008, que solicita una indemnización de $12.000 €$ por daños y perjuicios. A finales del ejercicio, el abogado de la empresa informa que, si bien es posible que haya que pagarle una indemnización, se puede estimar con fiabilidad que no excederá de 10.000€. Debido a la lentitud del proceso judicial, no se espera pagar la indemnización hasta finales de 2011. El tipo de actualización a utilizar es del 4\% (tipo de interés de mercado libre de riesgo).

\section{Solución.-}

A continuación se recoge el esquema financiero y la tabla de actualización de la provisión:

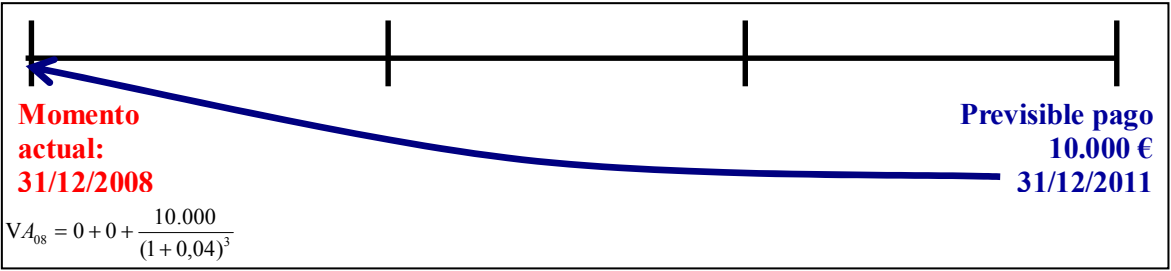

\begin{tabular}{|c|c|c|c|c|}
\hline & $\begin{array}{c}\text { Valor actual } \\
\text { 01-01 }\end{array}$ & \multicolumn{2}{|c|}{$\begin{array}{c}\text { Valor actual } \\
\mathbf{3 1 - 1 2}\end{array}$} & $\begin{array}{c}\text { Ajuste } \\
\text { provisión }\end{array}$ \\
\hline 2008 & - & $V A_{08}=0+0+\frac{10.000}{(1+0,04)^{3}}$ & $8.889,96$ & $\begin{array}{c}\text { Dotación provisión: } \\
8.889,96\end{array}$ \\
2009 & $8.889,96$ & $V A_{09}=0+\frac{10.000}{(1+0,04)^{2}}$ & $9.245,56$ & $\begin{array}{c}355,60 \\
\text { (Diferencia financiera) }\end{array}$ \\
\hline 2010 & $9.245,56$ & $V A_{10}=0+\frac{10.000}{(1+0,04)^{1}}$ & $9.615,38$ & $\begin{array}{c}369,82 \\
\text { (Diferencia financiera) }\end{array}$ \\
\hline 2011 & $9.615,38$ & $V A_{11}=10.000$ & $10.000,00$ & $\begin{array}{c}384,62 \\
\text { (Difencia financiera) }\end{array}$ \\
\hline
\end{tabular}

31-12-08:

$8.889,9 6 \longdiv { 6 7 8 \text { Gastos excepcionales } }$

a 142 Provisión para otras responsabilidades

$8.889,96$

31-12-09:

$355,60 \quad 660$ Gastos financieros por

a 142 Provisión para otras actualización de provisiones responsabilidades

31-12-10:

\begin{tabular}{cc}
369,82 & $\begin{array}{c}660 \text { Gastos financieros por } \\
\text { actualización de provisiones }\end{array}$ \\
\cline { 2 - 2 } $9.245,56$ & $\begin{array}{c}142 \text { Provisión para otras } \\
\text { responsabilidades }\end{array}$
\end{tabular}
5292 Provisión a c/p para otras responsabilidades
a 5292 Provisión a c/p para otras
responsabilidades

responsabilidades

31-12-11: 


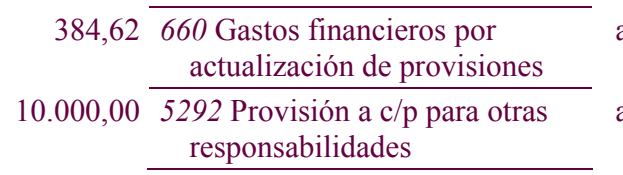
5292 Provisión a c/p para otras
responsabilidades
$\overline{572 \text { Bancos, } \mathrm{c} / \mathrm{c}, €} \quad 10.000,00$
384,62

Caso 2.- A finales del año 2008, la empresa "Cementos del Norte, S.A. (CEMERNOSA) recibe una notificación de la Junta de Castilla y León en la que le comunica que está contaminando las aguas fluviales y, según la legislación vigente, debe afrontar una sanción para reparaciones ambientales por un importe estimado de 2.500.000€. El abogado de la empresa informa que, aunque es altamente probable que CEMERNOSA tenga que afrontar la sanción, el proceso se dilatará en el tiempo unos dos años, debido a los distintos recursos que se pueden interponer. A finales del año 2008 el abogado estima que el importe final a pagar será de aproximadamente 2.200.000€. No obstante, a finales de 2009 revisa su estimación y considera que es más probable que el importe final de la provisión ascienda a 2.300.000€. Por último, a finales de 2010 el juez dicta sentencia, asciendo el importe definitivo de la sanción a 2.380.000€, que se pagan al contado. La tasa de actualización, teniendo presente el tipo de interés de las obligaciones del Tesoro es del 4,5\% (finales del año 2008) y 4,3\% (finales del año 2009).

\section{Solución.-}

Se trata de una provisión con un plazo de vencimiento superior a un año, por lo que será necesario calcular el valor actual de la mejor estimación de la provisión al cierre de cada uno de los ejercicios implicados (2008, 2009 y 2010), de acuerdo con el siguiente esquema inicial y tabla de actualización:

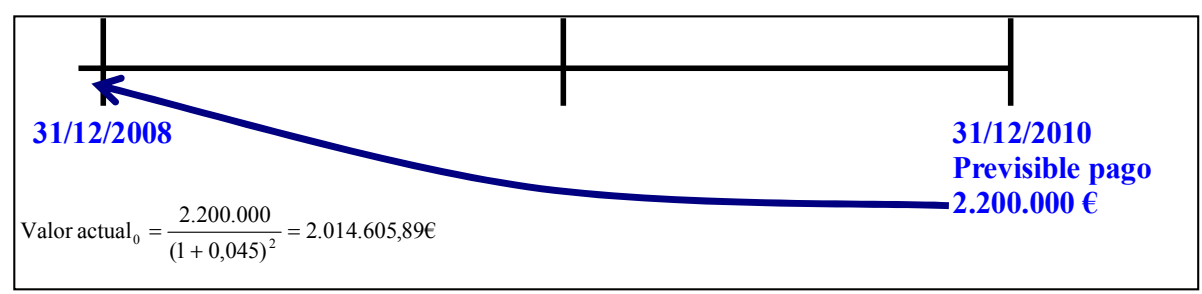

\begin{tabular}{|c|c|l|c|c|}
\hline & $\begin{array}{c}\text { Valor actual } \\
\mathbf{0 1 - 0 1}\end{array}$ & \multicolumn{1}{|c|}{$\begin{array}{c}\text { Valor actual } \\
\mathbf{3 1 - 1 2}\end{array}$} & $\begin{array}{c}\text { Ajuste } \\
\text { provisión }\end{array}$ \\
\hline 2008 & - & $V A_{08}=\frac{2.200 .000}{(1+0,045)^{2}}$ & $2.014 .605,89$ & $\begin{array}{c}\text { Dotación provisión: } \\
2.014 .605,89\end{array}$ \\
\hline \multirow{2}{*}{2009} & $2.014 .605,89$ & $V A_{09}=\frac{2.200 .000}{(1+0,043)^{1}}$ & $2.109 .300,09$ & $\begin{array}{c}94.694,20 \\
\text { (Diferencia financiera) }\end{array}$ \\
\cline { 2 - 5 } & & $V A_{09}=\frac{2.300 .000}{(1+0,043)^{1}}$ & $2.205 .177,37$ & $\begin{array}{c}95.877,28 \\
\text { (Dotación) }\end{array}$ \\
\hline 2010 & $2.205 .177,37$ & $V A_{10}=2.300 .000$ & $2.300 .000,00$ & $\begin{array}{c}94.822,63 \\
\text { (Diferencia financiera) }\end{array}$ \\
\hline
\end{tabular}

31-12-08: 


\begin{tabular}{|c|c|c|c|c|}
\hline \multirow[b]{2}{*}{$2.014 .605,89$} & \multirow[b]{2}{*}{678 Gastos excepcionales } & & \multirow[b]{2}{*}{$2.014 .605,89$} \\
\hline & & $\mathrm{a}$ & $\begin{array}{l}145 \text { Provisión para actuaciones } \\
\text { medioambientales }\end{array}$ & \\
\hline \multicolumn{5}{|l|}{ 31-12-09: } \\
\hline $94.694,20$ & $\begin{array}{l}660 \text { Gastos financieros por } \\
\text { actualización de provisiones }\end{array}$ & a & $\begin{array}{l}5295 \text { Provisión a c/p para } \\
\text { actuaciones medioambientales }\end{array}$ & $94.694,20$ \\
\hline $95.877,28$ & 678 Gastos excepcionales & a & $\begin{array}{l}5295 \text { Provisión a c/p para } \\
\text { actuaciones medioambientales }\end{array}$ & $95.877,28$ \\
\hline $2.014 .605,89$ & $\begin{array}{l}145 \text { Provisión para actuaciones } \\
\text { medioambientales }\end{array}$ & a & $\begin{array}{l}5295 \text { Provisión a c/p para } \\
\text { actuaciones medioambientales }\end{array}$ & $2.014 .605,89$ \\
\hline \multicolumn{5}{|l|}{ 31-12-10: } \\
\hline $94.822,63$ & $\begin{array}{l}660 \text { Gastos financieros por } \\
\text { actualización de provisiones }\end{array}$ & $\mathrm{a}$ & $\begin{array}{l}5295 \text { Provisión a c/p para } \\
\text { actuaciones medioambientales }\end{array}$ & $94.822,63$ \\
\hline $2.300 .000,00$ & $\begin{array}{l}5295 \text { Provisión a c/p para } \\
\text { actuaciones medioambientales }\end{array}$ & a & 572 Bancos, c/c, $€$ & $2.380 .000,00$ \\
\hline $80.000,00$ & 678 Gastos excepcionales & & & \\
\hline
\end{tabular}

Caso 3.- La empresa naviera "Prestixe, S.A." se dedica al transporte de fuel a lo largo del mundo. Debido a la naturaleza de sus actividades, ha exteriorizado parte de su riesgo mediante un contrato de seguros con la entidad "Seguros Aja", que cubre el 80\% del importe de las indemnizaciones que ocasione un hipotético siniestro. Durante el año 2008, se ha producido un vertido de fuel en las costas gallegas de extrema gravedad. Una vez evaluado el daño por los expertos, se ha estimado la cuantía de la actuación medioambiental necesaria en 7.000.000€, si bien el proceso durará tres años hasta que el pago sea efectivo. "Seguros Aja" ha manifestado a los afectados que asumirá directamente el riesgo que le corresponda. El interés legal del dinero es del 3,5\% anual. Contabilizar el importe de la provisión para el año 2008 .

\section{Solución.-}

En este caso existe un derecho de cobro a recibir de un tercero procedente de la externalización del riesgo, es decir, la responsabilidad del pago del $80 \%$ de la actuación no corresponde a la naviera sino directamente a la empresa "Axa".

$$
V A_{08}=\frac{20 \% \times 7.000 .000}{(1+0,035)^{3}}=1.262 .719,79 €
$$

31-12-08:

1.262.719,79 678 Gastos excepcionales a 145 Provisión para actuaciones medioambientales

\section{Si se comparan las normas de valoración del NPGC con las recogidas en el PGC'90 se observan diferencias significativas:}


1) El principio de prudencia no prevalece sobre lo demás, por lo que la existencia de incertidumbre no justifica el reconocimiento de provisiones sobrevaloradas.

2) El NPGC establece que la provisión se valore por el valor actual de los desembolsos de efectivo futuros, esto es, tiene en cuenta el efecto financiero cuando el vencimiento supera un año. El PGC'90 no hace referencia al valor actual, al no considerar el efecto financiero.

3) El NPGC regula la posibilidad de que se produzcan reembolsos de terceros relacionados con obligaciones, hecho no regulado en el PGC' 90 .

\subsection{Casos particulares de provisiones}

A continuación se recogen ciertos casos particulares de provisiones que requieren un tratamiento contable diferenciado según el NPGC.

\subsubsection{Contratos de carácter oneroso}

Algunos contratos pueden ser revocados sin satisfacer ninguna compensación a la otra parte $y$, en consecuencia, no producen ninguna obligación en el momento de su cancelación. Por el contrario, los contratos onerosos establecen obligaciones para su revocación, siendo definidos por el NPGC como aquellos contratos en los que los costes inevitables de cumplir con las obligaciones que conllevan exceden a los beneficios económicos que se esperan recibir de los mismos.

Estos contratos cumplen todos los requisitos para reconocer una provisión, pues representan una obligación presente de la entidad consecuencia de sucesos pasados (el contrato vigente de carácter oneroso), de cuantía incierta (el importe a pagar dependerá del momento de cancelación), por la que se espera que la empresa tenga que desprenderse de recursos que incorporen beneficios económicos y cuyo importe puede estimarse con fiabilidad.

La identificación de un contrato oneroso suele ser compleja, debido a la existencia de pérdidas de explotación derivadas de activos deteriorados o márgenes de beneficios insuficientes. Por ello, antes de reconocer la provisión debe realizarse un test de deterioro de los activos 
implicados en la explotación del contrato; si una vez reconocidos los posibles deterioros de los activos el contrato sigue teniendo costes inevitables que superan a los beneficios económicos esperados, se procederá al reconocimiento de la provisión correspondiente utilizando la cuenta "4994. Provisión por contratos onerosos" y, como contrapartida, la cuenta de gastos "6954. Dotación a la provisión por contratos onerosos".

Estas provisiones se reconocerán por un importe igual a los costes inevitables de cumplir el contrato, que según la NIC37 coincide con el menor de los siguientes importes:

- El coste neto de cumplir las cláusulas del contrato

- Las compensaciones o multas que se deriven del incumplimiento del contrato.

Los contratos onerosos no generan gastos financieros por actualización de valores, sino que son ajustados al final de cada ejercicio por la diferencia de valor debida a la actualización temporal de las compensaciones por incumplimiento, utilizando la cuenta "7954. Exceso de provisión por contratos onerosos"; esta cuenta se abonará también si la empresa decide cancelar el contrato oneroso que originó la provisión.

Ejemplo n ${ }^{0}$ 5.-

La empresa "LA CASA, S.A." emplea una fábrica alquilada para desarrollar sus actividades normales, en régimen de arrendamiento operativo, estando obligada a mantener el contrato hasta el año 2012. Durante el mes de diciembre del año 2008, la empresa traslada sus operaciones a una nueva fábrica. El arrendamiento fijo anual de la vieja fábrica asciende a 500.000€, pagadero por anticipado el 1 de enero de cada año, y estará en vigencia durante los próximos cuatro años. Para cancelar anticipadamente este contrato, la empresa tiene que hacer frente a una indemnización por importe de 1.950.000€ (2008), que se reduce un $25 \%$ por cada año transcurrido. El tipo de interés de mercado libre de riesgo es del 3,5\% anual (finales de 2008), 4,3\% (finales de 2009), 4,9\% (finales de 2010), 4,5\% (finales de 2011) y, 4,7\% (finales de 2012). Supóngase que:

Caso 1.- La empresa no puede subarrendar la fábrica

Solución.-

Para saber si existe un contrato de carácter oneroso y la cuantía de la provisión correspondiente deben calcularse los costes netos inevitables de mantener y cancelar el contrato para cada uno de los años implicados, de acuerdo con la siguiente tabla: 


\begin{tabular}{|c|c|c|c|c|}
\hline & $\begin{array}{c}\text { Valor actual } \\
\text { 01-01 }\end{array}$ & \multicolumn{2}{|c|}{$\begin{array}{c}\text { Valor actual 31-12 } \\
\text { Mínimo de: }\end{array}$} & $\begin{array}{c}\text { Ajuste } \\
\text { provisión }\end{array}$ \\
\cline { 3 - 4 } 2008 & - & $V A_{08}=\sum_{i=0}^{3} \frac{500.000}{(1+0,035)^{i}}=1.900 .818,49$ & 1.950 .000 & $\begin{array}{c}\text { Cotación provisión: } \\
1.900 .818,49\end{array}$ \\
\hline 2009 & $1.900 .818,49$ & $V A_{09}=\sum_{i=0}^{2} \frac{500.000}{(1+0,043)^{i}}=1.439 .009,00$ & $\begin{array}{c}75 \% 1.950 .000= \\
=1.462 .500\end{array}$ & $\begin{array}{c}-461.809,49 \\
\text { (Exceso) }\end{array}$ \\
\hline 2010 & $1.439 .009,00$ & $V A_{10}=\sum_{i=0}^{1} \frac{500.000}{(1+0,049)^{i}}=976.644,24$ & $\begin{array}{c}50 \% 1.950 .000= \\
=975.000\end{array}$ & $\begin{array}{c}-464.009,00 \\
\text { (Exceso) }\end{array}$ \\
\hline 2011 & $\begin{array}{l}\text { Si la empresa toma decisiones racionales, cancelará el contrato a comienzos del año 2011, } \\
\text { dado que le resulta más económica la cancelación que el mantenimiento. }\end{array}$ \\
\hline
\end{tabular}

\section{1-12-08:}

$$
\begin{array}{cc}
1.900 .818,49 & \begin{array}{c}
695 \text { Dotación a la provisión por } \\
\text { operaciones comerciales }
\end{array} \\
\hline
\end{array}
$$

\section{Provisión por contratos} onerosos

31-12-09:
461.809,49 4994 Provisión por contratos onerosos a 7954 Exceso de provisión por contratos onerosos

\section{1-12-10:}

\begin{tabular}{c} 
464.009,00 $\begin{array}{l}4994 \text { Provisión por contratos } \\
\text { onerosos }\end{array}$ \\
\hline
\end{tabular}

$\overline{7954 \text { Exceso de provisión por }}$
contratos onerosos

Enero-11:
975.000,00 4994 Provisión por contratos onerosos

Caso 2.- La empresa puede subarrendar la fábrica, obteniendo por ello 350.000€ anuales.

\section{Solución.-}

En este caso debe considerarse el alquiler de la nave al calcular el coste neto inevitable de mantener el contrato:

\begin{tabular}{|c|c|c|c|c|}
\hline & \multirow{2}{*}{$\begin{array}{c}\text { Valor } \\
\text { actual } \\
\text { 01-01 }\end{array}$} & \multicolumn{2}{|c|}{$\begin{array}{c}\text { Valor actual 31-12 } \\
\text { Mínimo de: }\end{array}$} & $\begin{array}{c}\text { Ajuste } \\
\text { provisión }\end{array}$ \\
\cline { 3 - 5 } 2008 & - & $V A_{08}=\sum_{i=0}^{3} \frac{500.000-350.000}{(1+0,035)^{i}}=570.245,55$ & 1.950 .000 & $\begin{array}{c}\text { Dotación } \\
\text { provisión: } \\
570.245,55\end{array}$ \\
\hline 2009 & $570.245,55$ & $V A_{09}=\sum_{i=0}^{2} \frac{500.000-350.000}{(1+0,043)^{i}}=431.702,70$ & $\begin{array}{c}75 \% 1.950 .000= \\
=1.462 .500\end{array}$ & $\begin{array}{c}-138.542,85 \\
\text { (Exceso) }\end{array}$ \\
\hline 2010 & $431.702,70$ & $V A_{10}=\sum_{i=0}^{1} \frac{500.000-350.000}{(1+0,049)^{i}}=292.993,33$ & $\begin{array}{c}50 \% 1.950 .000= \\
=975.000\end{array}$ & $\begin{array}{c}-138.709,33 \\
(\text { Exceso) }\end{array}$ \\
\hline
\end{tabular}




\begin{tabular}{|c|c|c|c|c|}
\hline 2011 & $292.993,33$ & $V A_{11}=500.000-350.000=150.000,00$ & $\begin{array}{c}25 \% 1.950 .000= \\
=487.500\end{array}$ & $\begin{array}{c}-142.993,33 \\
\text { (Exceso) }\end{array}$ \\
\hline 2012 & $150.000,00$ & $0 €($ vence el contrato oneroso) & $\begin{array}{c}-150.000,00 \\
\text { (Exceso) }\end{array}$ \\
\hline
\end{tabular}

\section{1-12-08:}
$570.245,5 5 \longdiv { 6 9 5 \text { Dotación a la provisión por } }$ operaciones comerciales

\section{Provisión por contratos} $\begin{array}{ll}\text { onerosos } & 570.245,55\end{array}$

31-12-09:

138.542,85 4994 Provisión por contratos onerosos

31-12-10:

138.709,37 4994 Provisión por contratos a

7954 Exceso de provisión por onerosos contratos onerosos

31-12-11:

142.993,33 4994 Provisión por contratos a 7954 Exceso de provisión por onerosos contratos onerosos

31-12-12:

$150.000,004994$ Provisión por contratos a 7954 Exceso de provisión por onerosos

\subsubsection{Reestructuraciones}

El NPGC define la reestructuración como "un programa de actuación planificado y controlado por la empresa, que produzca un cambio significativo en:

- El alcance de la actividad llevada a cabo por la empresa, o

- La manera de llevar la gestión de su actividad".

Entre los ejemplos más habituales de reestructuración destacan la venta o liquidación de una línea de actividad; la clausura de un emplazamiento de la empresa en un país o región; la reubicación de las actividades empresariales que se ejercían en un país o región a otros distintos; los cambios en la estructura de la gerencia tales como la eliminación de un nivel o escala de directivos empresariales; y otras reorganizaciones importantes que tienen un efecto significativo sobre la naturaleza y el enfoque de las actividades de la empresa. 
Estas provisiones, que constituyen una novedad del NPGC, permiten reconocer mediante la cuenta "146. Provisión para reestructuraciones" los costes que surjan directamente de la reestructuración, siempre y cuando se cumplan dos requisitos básicos de reconocimiento: (1) los costes estén necesariamente impuestos por la reestructuración; y (2) los costes no estén relacionados con las actividades que continúan en la empresa tras la reestructuración. De esta forma, la empresa sólo puede reconocer bajo la forma de provisión los costes derivados de actividades que desaparezcan de la empresa (despido de trabajadores, baja de activos fijos no reutilizables, etc.) pero no así aquéllos que afecten a la gestión futura de la entidad de cualquier forma (adiestramiento del personal para su reubicación, costes de comercialización o publicidad que benefician al resto de líneas de negocio, inversión en nuevos sistemas o redes de distribución, etc.).

Habitualmente no existe un contrato o causa legal que origine la obligación presente para la entidad, sino que es la propia empresa la que asume obligaciones implícitas derivadas de sus actuaciones. La NIC 37 amplía los requisitos necesarios para el reconocimiento de una provisión implícita para reestructuraciones; si bien estas exigencias no son de obligado cumplimiento para las empresas que aplican el NPGC, constituyen una guía de referencia útil en la práctica para establecer el momento de reconocimiento contable de estas provisiones:

1) La entidad debe tener una obligación presente, legal o implícita como consecuencia de la reestructuración. Existe una obligación implícita cuando la entidad tenga un plan formal y detallado de reestructuración, en el que se identifiquen, al menos, las actividades empresariales implicadas, las principales ubicaciones afectadas, la ubicación, función y número aproximado de los empleados que serán indemnizados tras prescindir de sus servicios, los desembolsos que se asumirán y las fechas en las que será implementado el plan. Como consecuencia del anuncio del plan o del comienzo del mismo, deben existir expectativas válidas entre los afectados en el sentido de que la reestructuración se llevará a cabo.

2) Es probable que la entidad tenga que desprenderse de recursos que incorporen beneficios económicos. En el de la venta de una línea de actividad, no surgirá ninguna obligación para la empresa al menos que exista un compromiso firme de venta, aunque se 
haya tomado la decisión y se haya anunciado públicamente la misma.

3) Pueda hacerse una estimación fiable del importe de la obligación a partir de los costes inevitables de las actividades que desaparecen de la empresa.

\section{Ejemplo n 6.-}

El día 12 de diciembre de 2008, la empresa farmacéutica "LINFARMA" decide abandonar el segmento de los medicamentos antivirales, de acuerdo con los siguientes datos:

Caso 1.- El órgano de administración de LINFARMA no comunica su decisión a ninguno de los afectados, ni toma ninguna otra medida para llevar a cabo la cláusula decidida.

\section{Solución.-}

En este caso no existe obligación presente, legal o implícita al cierre del ejercicio para la empresa, pues no existe un plan formal y detallado de reestructuración ni se han formado expectativas válidas entre los afectados. La empresa no debe dotar la provisión para reestructuraciones.

Caso 2.- El órgano de administración de LINFARMA elabora un plan de reestructuración a 6 meses y anuncia sus principales características a los empleados. La empresa estima que, como consecuencia de esta reestructuración, se van a producir los siguientes resultados:

\begin{tabular}{|c|c|}
\hline 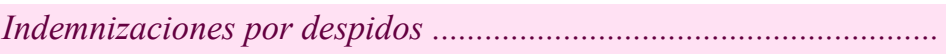 & $(300.000)$ \\
\hline Reubicación del personal ................... & $(15.000)$ \\
\hline Venta del inmueble de banca de grandes capitales (beneficio) ......... & 200.000 \\
\hline Menores gastos futuros de mantenimiento de activos materiales .... & \\
\hline
\end{tabular}

Finalmente la reestructuración se lleva a cabo a lo largo del año 2009, ascendiendo los importe reales a las siguientes cantidades:

\begin{tabular}{|c|c|}
\hline Indemnizaciones por despidos .............................. & $(290.000)$ \\
\hline Reubicación del personal ....... & $(18.000)$ \\
\hline Venta del inmueble de banca de grandes capitales (beneficio) ......... & 222.000 \\
\hline Menores gastos futuros de mantenimiento de activos materiales .... & 16.000 \\
\hline
\end{tabular}

\section{Solución.-}

La cuantía por el que se debe dotar la provisión no puede incluir importes asociados con actividades que continúan en la entidad (menores gastos futuros de mantenimiento de activos materiales), ni relacionados con formación o reubicación del personal que permanezca dentro de la empresa. Por su parte, los beneficios esperados por la venta de 
activos no se incluyen dentro de la provisión ni minoran su importe, de acuerdo con los criterios comentados para la mejor estimación del importe de una provisión.

De esta forma, el importe de la provisión debería ser de $300.000 €$ (correspondientes a las indemnizaciones por despidos).

\section{1-12-08:}

$300.000,00$

641 Indemnizaciones

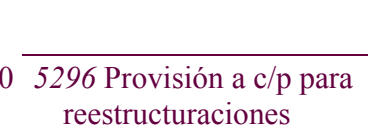

a

5296 Provisión a c/p para

reestructuraciones

2009:
$300.000,00$

$290.000,00$

$10.000,00$

inmovilizado

1.4.3. Desmantelamiento, retiro o rehabilitación del

La cuenta "143. Provisión por desmantelamiento, retiro o rehabilitación del inmovilizado" se destina a reconocer los importes estimados de los costes de desmantelamiento o retiro del inmovilizado, incluyendo la rehabilitación del lugar en que éste se asienta.

La empresa puede incurrir en estas obligaciones en el momento de adquirir el inmovilizado o para poder utilizar el mismo durante un determinado periodo de tiempo, distinguiéndose dos situaciones a efectos de su tratamiento contable:

1) Si se incurre en la obligación como consecuencia de haber utilizado el inmovilizado para producir existencias, el reconocimiento y la valoración de la provisión siguen los criterios generales previamente comentados.

2) Si se incurre en la obligación en el momento de adquirir el inmovilizado, o como consecuencia de su utilización para un propósito distinto a la producción de existencias, la provisión se rige por lo establecido en la Norma de Registro y Valoración $n^{\circ} 2$ "Inmovilizado Material"".

6 Según la Norma de Valoración y Registro $\mathrm{n}^{\circ} 2$ "formará parte del valor del inmovilizado material la estimación inicial del valor actual de las obligaciones asumidas derivadas del desmantelamiento o retiro y otras asociadas a citado activo, tales como los costes de rehabilitación del lugar sobre el que se asienta, siempre que estas obligaciones den lugar al registro de provisiones". 
En el segundo caso, la provisión se abona al nacimiento de la provisión, o por incrementos posteriores en su importe, con cargo generalmente a cuentas del subgrupo "21. Inmovilizaciones Materiales". La correspondiente actualización financiera se registra anualmente con cargo a la cuenta "660. Gastos financieros por actualización de provisiones". Si al cierre del ejercicio se produce una disminución del importe de la provisión como consecuencia de una nueva estimación de su importe, se abonará la cuenta correspondiente del subgrupo 21 . Finalmente, la provisión se dará de baja en el momento de su aplicación, con cargo a cuentas de tesorería o, en su caso, a la cuenta "795. Exceso de provisiones".

De esta forma, el efecto de cualquier cambio en una obligación existente para los costes de desmantelamiento o retiro se suma o resta al coste del activo relacionado y se amortiza en el futuro a lo largo de la vida útil restante, es decir, se trata de un cambio en la estimación.

Cabe destacar que esta provisión no está destinada a recoger los importes previstos para grandes reparaciones del activo fijo (flotas de naves, aeronaves, etc.), pues según el NPGC cuando la empresa adquiere un elemento sujeto a revisión periódica no tiene la obligación actual de realizar la revisión ${ }^{7}$, por lo que no sería acorde a la definición de pasivo el registro de su coste y, por tanto, el reconocimiento de la provisión. Como alternativa, la Norma de Registro y Valoración $n^{\circ} 3$ "Normas Particulares sobre Inmovilizado Material" establece que el importe equivalente a los costes relacionados con grandes reparaciones del inmovilizado se amortizará de forma distinta a la del resto del elemento durante el periodo que medie hasta la gran reparación. En el momento en que tenga lugar la gran reparación, su coste se reconocerá en el valor neto contable del inmovilizado como una sustitución, siempre que se cumplan las condiciones para su reconocimiento, dándose de baja cualquier importe asociado a la reparación que pudiera permanecer en el valor contable del inmovilizado.

Si se compara este nuevo tratamiento con el establecido por el PGC de 1990 para la provisión para grandes reparaciones pueden observarse varias diferencias que afectan tanto al Balance de Situación

7 Por ejemplo, la empresa podría no realizar la revisión en el futuro si vende los 
como a la Cuenta de Pérdidas y Ganancias de la empresa. Entre los principales efectos destaca el registro, según el NPGC, de un pasivo inferior al PGC de 1990, dado que el coste de la reparación futura no incrementa el endeudamiento de la empresa. Asimismo, el valor neto contable del activo se renovará periódicamente, incorporando los importes sucesivos de la gran reparación que previsiblemente se irán incrementando debido a la inflación, mientras que el PGC de 1990 amortiza el coste inicial del activo fijo como un único elemento y en un único periodo de vida útil, sin considerar las modificaciones sufridas a lo largo del tiempo. Finalmente, la amortización del coste de la reparación durante el periodo que media hasta su realización, según el NPGC, permite una mejor correlación entre el coste total del elemento (coste de adquisición más plan de revisión) y los ingresos generados por el mismo.

\section{Ejemplo n ${ }^{\circ}$ 7.-}

El día 5 de enero de 2008 la empresa "RIOPINTO" adquiere a crédito (corto plazo) una balsa para verter y tratar residuos por importe de 654.000€, de los que 190.000€ corresponden al coste del terreno y el resto al coste de la construcción, estimándose su vida útil en 20 años.

Cada 5 años se precisa realizar una gran reparación sobre las paredes de la balsa (que representa el $40 \%$ del coste de la construcción) y llevar a cabo, además, un proceso de rehabilitación del lugar en el que se asienta. Aunque se desconoce el coste futuro de la rehabilitación medioambiental, se sabe que en el momento actual su coste es de 101.466€, y en el futuro se estima un incremento del coste similar al IPC, previsto en un 3\%. La tasa de actualización teniendo presentes los riesgos específicos de la compañia es del 5,5\%.

Al cabo de los cinco años, el coste de la rehabilitación asciende a 108.860€. Por su parte, el coste de la gran reparación de la balsa asciende a 195.000€.

De acuerdo con el NPGC, contabilicense los hechos patrimoniales relacionados con el inmovilizado de la empresa durante los primeros 5 años de vida útil.

Solución.-

En este caso existen dos conceptos diferentes relacionados con la balsa:

(a) La gran reparación que debe realizarse sobre la balsa, que se trata como una sustitución o mejora a efectos contables:

\begin{tabular}{|c|c|}
\hline Terrenos (no se amortizan) & 190.000 \\
\hline $\begin{array}{l}\text { Paredes de la balsa (gran reparación cada } 5 \text { años) } \\
\quad 40 \%(654.000-190.000)\end{array}$ & 185.600 \\
\hline Resto de la balsa (vida útil: 20 años) & 278.400 \\
\hline TOTAL & 654.000 \\
\hline
\end{tabular}


(b) El proceso de rehabilitación del lugar en el que se asienta, que da lugar al reconocimiento de una provisión por desmantelamiento, retiro o rehabilitación del inmovilizado. Para contabilizar la provisión debe realizarse:

a. Una estimación del precio futuro de la rehabilitación según el IPC:

$$
101.466 \times(1+0,03)^{5}=117.626,90
$$

b. La actualización del precio final para los distintos ejercicios contables:

$$
\text { Valor actual año } i=\frac{117.626,90}{(1+i)^{5-\mathrm{i}}}=\frac{117.626,90}{(1+0,055)^{5-\mathrm{i}}}
$$

\begin{tabular}{|c|c|c|c|c|}
\hline \multirow{2}{*}{2008} & $\begin{array}{c}\text { Valor actual 1-1 } \\
(\approx \mathbf{5 - 1})\end{array}$ & \multicolumn{1}{|c|}{ Valor actual 31-12 } & $\begin{array}{c}\text { Ajuste } \\
\text { provisión }\end{array}$ \\
\hline & $V A_{\text {Enero }-08}=\frac{117.626,90}{(1+0,055)^{5}}=90.000,38$ & & $\begin{array}{c}\text { Dotación provisión: } \\
90.000,38\end{array}$ \\
\hline 2009 & $90.000,38$ & $V A_{08}=\frac{117.626,90}{(1+0,055)^{4}}$ & $94.950,40$ & $\begin{array}{c}4.950,02 \\
\text { (Difer. financiera) }\end{array}$ \\
\hline 2010 & $94.950,41$ & $V A_{09}=\frac{117.626,90}{(1+0,055)^{3}}$ & $100.172,68$ & $\begin{array}{c}5.222,27 \\
\text { (Difer. financiera) }\end{array}$ \\
\hline 2011 & $100.172,68$ & $V A_{10}=\frac{117.626,90}{(1+0,055)^{2}}$ & $105.682,18$ & $\begin{array}{c}5.509,50 \\
\text { (Difer. financiera) }\end{array}$ \\
\hline 2012 & $105.682,18$ & $V A_{11}=\frac{117.626,90}{(1+0,055)^{1}}$ & $111.494,69$ & $\begin{array}{c}5.812,52 \\
\text { (Difer. financiera) }\end{array}$ \\
\hline 2013 & $111.494,69$ & $V A_{12}=\frac{117.626,90}{(1+0,055)^{0}}$ & $117.626,90$ & $\begin{array}{c}6.132,21 \\
\text { (Difer. financiera) }\end{array}$ \\
\hline
\end{tabular}

\section{5-1-08:}

$190.000,00 \quad 210$ Terrenos y bienes naturales

$278.400,002110$ Construcciones

185.600,00 2111 Construcciones (gran

90.000,38 $\frac{\text { reparación) }}{\begin{array}{c}2112 \text { Construcciones } \\ \text { (rehabilitación) }\end{array}}$ a

\begin{aligned} $13.920,00 & \begin{array}{l}681 \text { Amortización del } \\ \text { inmovilizado material } \\ (278.400 / 20)\end{array} \\$\cline { 2 - 2 } $55.120,08 & \begin{array}{c}681 \text { Amortización del } \\ \text { inmovilizado material } \\ (186.500 / 5+90.000,38 / 5)\end{array} \\ 4.950,03 & \begin{array}{l}660 \text { Gastos financieros por } \\ \text { actualización de provisiones }\end{array}\end{aligned}$

a 523 Proveedores de inmovilizado a c/p

$654.000,00$

143 Provisión por
desmantelamiento, retiro o
rehabilitación del inmovilizado

$90.000,38$

\section{Amortización acumulada construcciones}

a 28111 Amortización acumul. construcciones (reparación) a 28112 Amortización acumul. construcciones (rehabilitación)

$18.000,08$

a 143 Provisión por desmantelamiento, retiro o rehabilitación del inmovilizado 


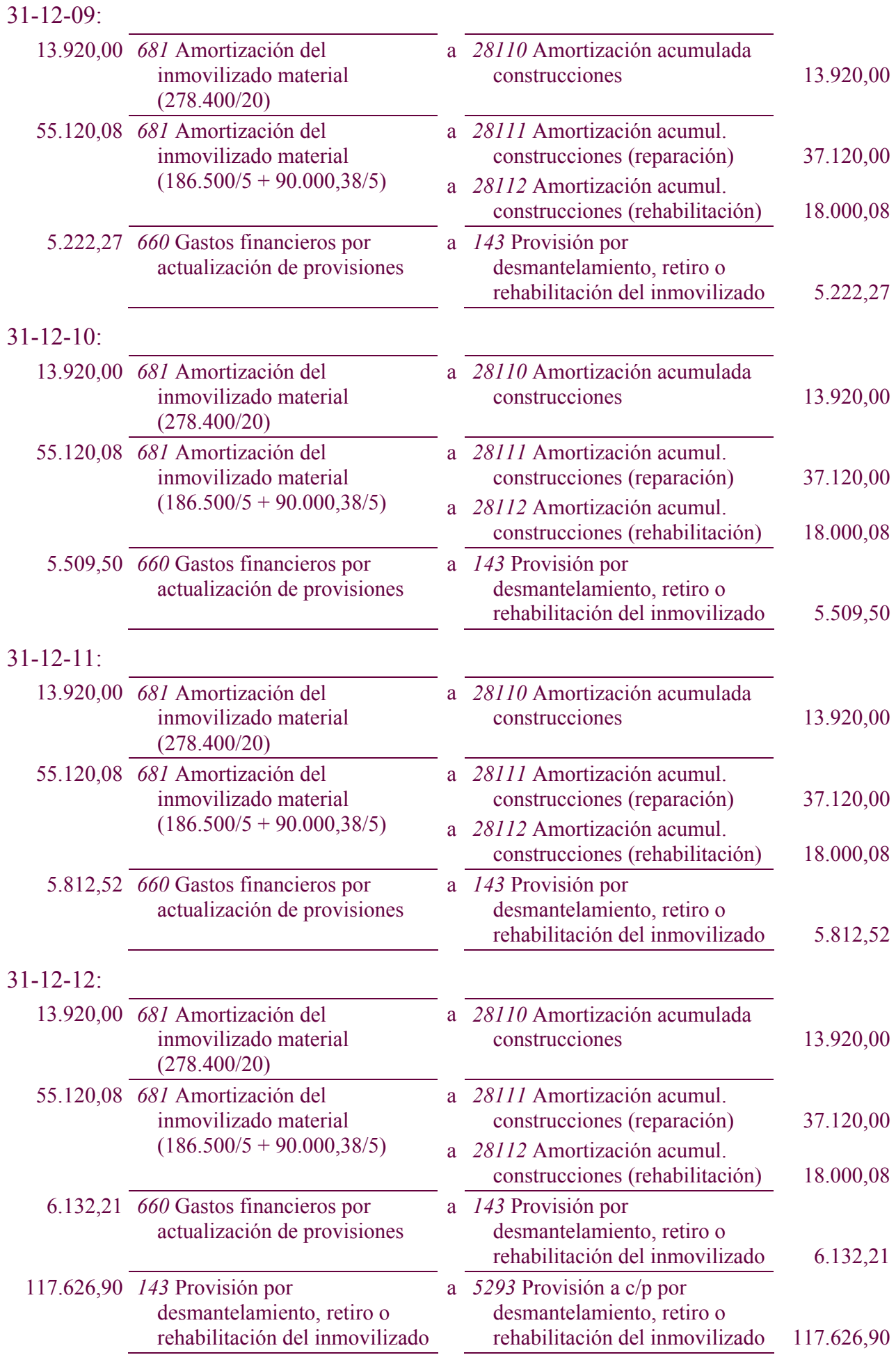


Por la gran reparación (195.000€):

5-1-13:

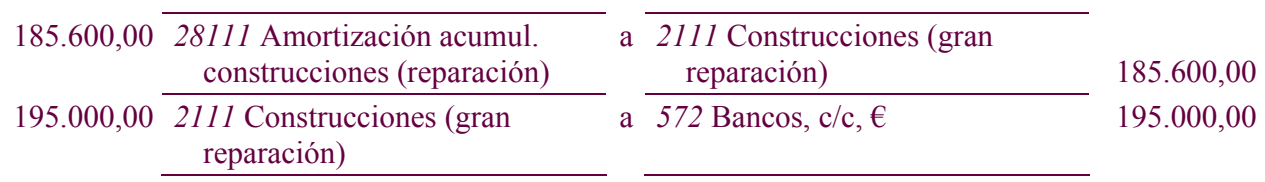

Por la rehabilitación del lugar en el que se asienta el inmovilizado (108.860€):

5-1-13:

\begin{tabular}{|c|c|c|}
\hline $90.000,38$ & $\begin{array}{l}28112 \text { Amortización acumul. } \\
\text { construcciones (rehabilitación) }\end{array}$ & $\begin{array}{l}\text { a } 2112 \text { Construcciones } \\
\text { (rehabilitación) }\end{array}$ \\
\hline $117.626,90$ & $\begin{array}{l}5293 \text { Provisión a c/p por } \\
\text { desmantelamiento, retiro o } \\
\text { rehabilitación del inmovilizado }\end{array}$ & $\begin{array}{l}\text { a } 572 \text { Bancos, c/c, } € \\
\text { a } 795 \text { Exceso de provisiones }\end{array}$ \\
\hline
\end{tabular}

\subsubsection{Retribuciones y otras prestaciones al personal}

La importancia de los pasivos por retribuciones al personal ha llevado a su tratamiento diferenciado respecto del resto de provisiones, dedicándose la Norma de Registro y Valoración $n^{\circ} 16$ a este tipo de transacciones, excepto las basadas en instrumentos de patrimonio, que son reguladas en la norma 17 . Se consideran retribuciones a largo plazo al personal las prestaciones post-empleo, tales como pensiones y otras prestaciones por jubilación o retiro, así como cualquier otra prestación a largo plazo que suponga una compensación económica a satisfacer con carácter diferido respecto al momento en que se presta el servicio.

A efectos de su tratamiento contable, se distinguen dos tipos de retribuciones al personal:

- Las retribuciones a largo plazo de aportación definida: En este caso la empresa realiza contribuciones preestablecidas a una entidad separada (tradicionalmente una aseguradora o un plan de pensiones), que será la encargada de entregar las correspondientes prestaciones a los empleados en el momento de su vencimiento. De esta forma, la empresa no asume riesgos financieros ni actuariales como consecuencia de esta transacción, dado que no tiene la obligación legal, contractual o implícita de realizar contribuciones adicionales si la entidad separada no puede atender los compromisos asumidos. Dado que no existe una obligación presente sujeta a incertidumbre, estas transacciones 
no se contabilizan mediante provisiones sino que darán lugar a un pasivo cierto por retribuciones al personal si, al cierre del ejercicio, figuran contribuciones devengadas no pagadas.

- Las retribuciones a largo plazo de prestación definida: Todas aquellas retribuciones a largo plazo que no tengan el carácter de aportación definida se considerarán de prestación definida. En este caso la empresa asume algún tipo de riesgo financiero y/o actuarial como consecuencia de la transacción, por lo que existe una obligación presente, consecuencia de sucesos pasados, sujeta a incertidumbre que se registrará mediante la cuenta "140. Provisión por retribuciones a largo plazo al personal".

Para entender mejor la diferencia entre ambos tipos de retribuciones, supóngase que la empresa se compromete a pagar todos los años una cuota predeterminada a una entidad financiera, para que sus trabajadores reciban una pensión en el momento de su jubilación. Si la empresa sólo se compromete a pagar la cuota anual, sin ser responsable del abono de las cantidades en el momento de la jubilación, el compromiso se considerará de aportación definida. Si la empresa, además de comprometerse al pago de la cuota, asume la obligación de pagar una pensión a los trabajadores en el caso que la entidad financiera resulte insolvente, se considerará de prestación definida.

Si se consideran las retribuciones de prestación definida, el NPGC establece la necesidad de estimar el importe de la provisión mediante métodos actuariales de cálculo e hipótesis financieras y actuariales insesgadas y compatibles entre sí. El importe a reconocer en la cuenta "140. Provisión por retribuciones a largo plazo al personal" será la diferencia, en la fecha de cierre del ejercicio, entre el valor actual de las retribuciones comprometidas (según cálculos actuariales) y el valor razonable de los activos afectos ${ }^{8}$ al plan de retribuciones subyacente. Si como consecuencia de esta comparación surgiera un activo se reconocerá en el Balance, imputándose cualquier ajuste en su valoración por este límite a patrimonio neto, reconociéndose como reservas (Tabla 2).

$8 \quad$ Se entiende por activos afectos aquellos que no sean propiedad de la empresa sino de un tercero separado legalmente y que sólo estén disponibles para la liquidación de las retribuciones a los empleados, incluyendo las pólizas de seguros. 
Tabla 2. Valoración de las retribuciones de prestación definida

\begin{tabular}{|c|c|c|}
\hline Situación & $\begin{array}{c}\text { Reconocimiento } \\
\text { contable en el Balance }\end{array}$ & Importe \\
\hline Si VA $>$ VR & Provisión & VA - VR \\
\hline Si VA $<$ VR & Activo & $\begin{array}{c}\text { VR - VA } \\
\text { (límite: valor actual de las prestaciones económicas que } \\
\text { pueden retornar a la empresa en forma de reembolsos } \\
\text { directos o menores contribuciones futuras + parte pendiente } \\
\text { de imputar a resultados de costes por servicios pasados). }\end{array}$ \\
\hline VA: Valor actual de las retribuciones comprometidas (cálculo actuarial según hipótesis) \\
VR; Valor razonable de los activos afectos al plan.
\end{tabular}

Fuente: Elaboración propia.

La provisión se reconocerá inicialmente utilizando la cuenta más apropiada del subgrupo "64. Gastos de personal", generalmente una de las subcuentas de la "644. Retribuciones a largo plazo mediante sistemas de prestación definida"; todas las variaciones en los valores actuales que se produzcan en el ejercicio se reconocerán en la cuenta de pérdidas y ganancias, excepto las variaciones debidas exclusivamente a pérdidas y ganancias actuariales que se imputarán directamente en el patrimonio neto, reconociéndose como reservas.

Con carácter general, los costes por servicios pasados se reconocerán inmediatamente como gastos en la cuenta de pérdidas y ganancias por su valor actual. Si estos costes han surgido por el establecimiento de un plan de retribuciones a largo plazo de prestación definida post-empleo o por una mejora en las condiciones del mismo, se imputarán a la Cuenta de Pérdidas y Ganancias de forma inmediata (si se trata de derechos irrevocables) o de forma lineal en el periodo que queda hasta que los derechos sean irrevocables (si se trata de derechos revocables; si en algún momento surgiera un activo, los derechos revocables se imputarán de forma inmediata a la cuenta de Pérdidas y Ganancias.

El tratamiento propuesto por el NPGC difiere de forma significativa del previsto en el PGC'90, que destinaba la provisión para pensiones y obligaciones similares a la dotación de fondos internos de jubilación y asimilados. Estos fondos internos fueron creados por las empresas de forma mayoritaria antes de 1995 y en todo caso antes de 2002, pues el Real Decreto Legislativo 1/2002 prohíbe estos compromisos y circunscribe su creación, con carácter excepcional, para las entidades de crédito, aseguradoras, sociedades y agencias de valores. Ahora bien, el NPGC extiende el reconocimiento de la provisión por retribuciones a largo 
de prestación definida no sólo a las entidades con fondos internos, sino también a las empresas con fondos exteriorizados que tengan la obligación solidaria de satisfacer los compromisos si la empresa externa incumple sus deberes al vencimiento.

\section{Ejemplo n 8.-}

De acuerdo con el NPGC, contabilicense los siguientes hechos patrimoniales relacionados con retribuciones al personal de la empresa:

Caso 1.- Debido a una reciente adquisición, la empresa "PLASMA" acuerda en diciembre de 2008 el cierre de una fábrica dentro de los 12 meses siguientes, procediendo entonces al despido de todos los empleados del centro. Como la empresa necesita concluir ciertos contratos, anuncia el siguiente plan de indemnizaciones: cada empleado que continúe en su puesto prestando servicios recibirá una indemnización en metálico de 45.000€, además del importe mínimo que determina la legislación vigente (15.000€ por empleado). En la fábrica hay 100 empleados, y se espera que 15 abandonen voluntariamente su puesto de trabajo antes del cierre.

\section{Solución.-}

En este caso la obligación con terceros se deriva de indemnizaciones por despido en un plazo inferior a 12 meses, por lo que no resulta necesario actualizar los importes correspondientes a las retribuciones comprometidas (no existen activos afectos al plan).

Las prestaciones a pagar serán:

- Según la legislación: 100 trabajadores $\times 15.000 € /$ trabajador $=1.500 .000 €$

- Por continuidad en puesto de trabajo: $(100-15) \times 45.000=3.825 .000 €$

31-12-08:

\begin{tabular}{|c|c|c|}
\hline $5.325 .000,00$ & $\begin{array}{l}641 \text { Indemnizaciones } \\
\quad(1.500 .000+3.825 .000)\end{array}$ & $\begin{array}{l}\text { a } 5290 \text { Provisión a c/p por } \\
\text { retribuciones al personal }\end{array}$ \\
\hline
\end{tabular}

Caso 2.- La empresa "Tito Lucas, S.A." constituye en el año 2008 un plan de aportaciones definidas para sus trabajadores, que consiste en una aportación anual de 100.000€ a realizar a la entidad aseguradora "Seguros León, S.A.", sin que "Tito Lucas" tenga la obligación legal de realizar contribuciones adicionales en caso que la entidad aseguradora no pueda atender los compromisos asumidos. La cuantía de la aportación se incrementará anualmente en un $4 \%$.

\section{Solución.-}

Dado que la empresa no asume ningún riesgo financiero ni actuarial como consecuencia de la operación, se trata de una retribución de aportación definida, ascendiendo el importe de la cuota anual a pagar a $100.000 €$ para el año 2008, $104.000 €$ para el año 2009, etc. 
31-12-08:

\begin{tabular}{cc}
\cline { 2 - 3 } $100.000,00$ & $\begin{array}{c}643 \text { Retribuciones a largo plazo } \\
\text { mediante sistemas de } \\
\text { aportación definida }\end{array}$
\end{tabular}

media on definida

\begin{tabular}{l} 
a 572 Bancos, c/c, $€$, o \\
466 Remuneraciones mediante \\
sistemas de aportación \\
definida pendientes de pago \\
\hline
\end{tabular}

$100.000,00$

31-12-09:

\begin{tabular}{cc}
\cline { 2 - 3 } 104.000,00 & $\begin{array}{c}643 \text { Retribuciones a largo plazo } \\
\text { mediante sistemas de } \\
\text { aportación definida }\end{array}$
\end{tabular}

Caso 3.- La sociedad "PURRI, SA" constituye en el año 2008 un plan de retribuciones a largo plazo de prestación definida con el personal de la empresa. A 31-12-08, en relación con dichas retribuciones se sabe lo siguiente:

$$
\begin{aligned}
& \text { Valor actual de las retribuciones comprometidas .................... } \\
& \text { Valor razonable de los activos afectos a los compromisos con } \\
& \text { los que se liquidarán las obligaciones ..................................... }
\end{aligned}
$$

El importe del valor actual de las retribuciones comprometidas se ha calculado por un actuario de seguros, que ha utilizado métodos actuariales de cálculo e hipótesis financieras y actuariales insesgadas y compatibles entre sí.

\section{Solución.-}

Para determinar si debe dotarse una provisión en lugar de un activo debe comprobarse que:

Valor actual retribuciones comprometidas $>$ Valor razonable activos afectos

$$
610.000>550.000
$$

31-12-08:

$60.000,00 \quad 6440$ Contribuciones anuales $(610.000-550.000)$
140 Provisión por retribuciones a largo plazo al personal

Caso 4.- Considérense los datos de la empresa "PURRI, SA", si bien en este caso el valor actual de las retribuciones comprometidas asciende a 550.000€ y el valor razonable de los activos afectos a los compromisos con los que se liquidarán las obligaciones es de $610.000 €$.

\section{Solución.-}

En este caso debe reconocerse un activo en el Balance de Situación, pues:

Valor actual retribuciones comprometidas $<$ Valor razonable activos afectos

$$
550.000<610.000
$$

31-12-08:

$60.000,0 0 \longdiv { 2 5 7 . 1 \text { Activos por retribuciones } }$ a largo plazo de prestación definida
a 951 Ajustes positivos en activos por retribuciones a largo plazo de prestación definida

$60.000,00$ 

$60.000,0 0 \longdiv { 9 5 1 \text { Ajustes positivos en activos } }$ por retribuciones a largo plazo de prestación definida

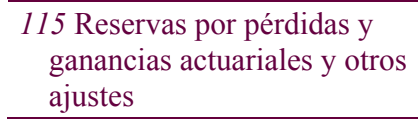

$60.000,00$

\section{LOS CAMBIOS EN LOS CRITERIOS CONTABLES}

La Norma de Registro y Valoración $\mathrm{n}^{\circ} 22$ del NPGC incluye el tratamiento de tres conceptos principales: los cambios en criterios contables, los cambios en las estimaciones contables, y la corrección de los errores materiales cometidos en la contabilización de hechos económicos. Estos conceptos presentan diversas analogías que pueden dificultar su identificación y reconocimiento contable, por lo que son objeto de estudio particular a continuación.

\subsection{Cambios en criterios contables: Razón de ser}

El principio de uniformidad incluido en el Marco Conceptual del NPGC establece que, una vez adoptado un criterio en la aplicación de los principios contables, dentro de las alternativas que en su caso se permitan, deberá mantenerse en el tiempo y aplicarse a transacciones similares si no se alteran los supuestos que motivaron tal elección, al objeto de facilitar los análisis comparativos de la información contable a lo largo del tiempo. Ahora bien, si se alteran los supuestos que provocaron que la entidad adoptara dicho criterio contable, podrá realizarse el cambio, siempre que se indique en la Memoria la incidencia cuantitativa y cualitativa de dicho cambio sobre las Cuentas Anuales, así como su justificación.

De esta forma, la uniformidad en la formulación de la información contable, como soporte de su comparabilidad y fiabilidad, puede verse alterada por una serie de cambios en los métodos, criterios, bases y procedimientos contables que implicarán modificaciones en las cifras presentadas en las Cuentas Anuales. Los cambios en los criterios contables pueden tener una doble naturaleza:

- Obligatoria: Consecuencia de la adopción de una nueva norma legal o revisada, respecto a elementos patrimoniales que se estaban valorando de acuerdo con normas anteriores. Por ejemplo: los ajustes derivados de la transición desde el PGC de 1990 hasta el NPGC constituyen un ejemplo de cambio obligatorio de criterios contables. 
- Voluntaria: Destinada a conseguir una presentación más adecuada de los sucesos y transacciones en los estados contables de la empresa. En este caso la justificación de las razones del cambio y la presentación de información comparativa entre los antiguos y los nuevos criterios resulta esencial para evitar distorsiones y manipulaciones contables que respondan a los objetivos de un grupo específico de usuarios (generalmente, los gestores o los propietarios) en perjuicio del resto de destinatarios de la información. Por ejemplo: Cambio del criterio de valoración FIFO para la valoración de existencias al coste promedio ponderado.

\subsection{Reconocimiento y registro contable}

De acuerdo con la Norma de Registro y Valoración $n^{\circ} 22$ "Cambios en criterios contables, errores y estimaciones contables", cuando se produzca un cambio de criterio contable se aplicará de forma retroactiva, y su efecto habrá de calcularse desde el ejercicio más antiguo para el que se disponga de información. Si no se dispone de datos pasados, se ajustará únicamente la información contable del ejercicio.

La aplicación retrospectiva del cambio, como si la nueva política contable siempre se hubiera utilizado, implica que el nuevo criterio se aplica a los sucesos y operaciones desde la misma fecha en que se originaron las partidas correspondientes, incluyendo cualquier efecto impositivo corriente o diferido. A efectos contables, esto supone que:

1. El efecto acumulado de las variaciones de los activos y pasivos que se derive de dicha aplicación motivará, en el ejercicio en que se produce el cambio, el correspondiente ajuste contable contra patrimonio neto. En concreto, se registrará en una partida de reservas, habitualmente la cuenta "113. Reservas voluntarias", salvo que el cambio de criterio afecte a un gasto o a un ingreso que hubiese sido contabilizado en su momento en otra cuenta de patrimonio neto.

2. Se modificarán las cifras afectadas en la información comparativa de los ejercicios a los que afecte el cambio, a menos que no sea posible realizarlo.

3. Se incluirá información detallada del ajuste en el apartado "2.7. Cambios de criterios contables" de la Memoria del ejercicio en el que se realice el cambio (modelo normal). En particular, debe 
informarse sobre la naturaleza del cambio, el importe de la corrección en cada ejercicio y la información comparativa realizada.

4. El ajuste contable ha de reflejarse de forma separada en el Estado de Cambios del Patrimonio Neto, como un ajuste del saldo inicial del ejercicio en el que se produce el cambio 9 .

Este tratamiento posee trascendencia no sólo contable, sino también mercantil, pues afecta al patrimonio final de ejercicios que ya habían sido formalmente aprobados por sus propietarios, siendo también necesario reexpresar las cifras de las partidas afectadas en la información comparativa de los estados financieros de años anteriores. En consecuencia, puede ser necesario formular de nuevo estados financieros previamente aprobados, lo que puede requerir modificaciones en la normativa legal, como por ejemplo, el Reglamento del Registro Mercantil.

Ahora bien, este nuevo tratamiento sí resulta coherente con la definición de patrimonio neto incluida en el Marco Conceptual del NPGC, que se asocia con la parte residual de los activos una vez deducidos todos sus pasivos ${ }^{10}$, abarcando un concepto más amplio que los fondos propios definidos en el PGC de 1990.

Las nuevas normas amplían y desarrollan la regulación incluida en el PGC de 1990 que, si bien contemplaba la aplicación retrospectiva de los cambios voluntarios de criterios contables, incluía las variaciones patrimoniales derivadas como resultado extraordinario en la Cuenta de Pérdidas y Ganancias del ejercicio en el que se producía el cambio, con la consiguiente distorsión de las cifras contables.

10 El patrimonio neto que aparecerá en los balances diseñados por el NPGC comprende, al margen de las partidas tradicionales, conceptos como las variaciones derivadas de la aplicación del criterio del valor razonable imputadas directamente al patrimonio, el efecto de los cambios en las políticas contables o de la corrección de errores, el efecto de las diferencias de conversión de estados financieros de sociedades dependientes, etc. 


\section{Ejemplo $n^{0}$ 9.-}

El 1-1-08 la empresa MAQUINOSA posee en su Balance de Situación una maquinaria adquirida el día 1-1-06 por un precio de adquisición de 16.000€, que entró en funcionamiento en la misma fecha. La amortización se viene realizando de forma lineal, considerando una vida útil de 4 años, sin valor residual.

A lo largo del año 2008 se realiza un estudio técnico que pone de manifiesto que, si bien la vida útil se espera razonablemente que abarque los 4 años previstos, el elemento se deprecia cada año de manera incremental respecto al ejercicio anterior, por lo que se decide cambiar el sistema de amortización y aplicar el método de números dígitos crecientes.

\section{Solución.-}

En este caso el cambio del criterio de amortización lineal por el criterio de amortización basado en números dígitos crecientes está justificado de acuerdo con el principio de uniformidad, pues se han modificado las circunstancias que motivaron la elección del método original, al observarse una depreciación creciente de la maquinaria respecto al deterioro lineal inicialmente estimado. Para determinar el efecto acumulado de las variaciones de activos y pasivos motivado por el cambio, debe aplicarse de forma retroactiva el nuevo criterio y compararlo con la amortización originalmente practicada. Se supone que el cambio de criterio tiene lugar a comienzos del año 2008.

\begin{tabular}{|c|c|c|c|}
\hline & $\begin{array}{c}\text { Cuota de amortización método } \\
\text { de números dígitos crecientes }\end{array}$ & $\begin{array}{c}\text { Cuota de amortización } \\
\text { método lineal }\end{array}$ & $\begin{array}{c}\text { Diferencia respecto a la } \\
\text { contabilización inicial }\end{array}$ \\
\hline 2006 & $\frac{16.000}{1+2+3+4} \times 1=1.600$ & $16.000 / 4=4.000$ & -2.400 \\
\hline 2007 & $\frac{16.000}{1+2+3+4} \times 2=3.200$ & 4.000 & -800 \\
\hline Total & $\mathbf{4 . 8 0 0}$ & $\mathbf{8 . 0 0 0}$ & $\mathbf{- 3 . 2 0 0}$ \\
\hline
\end{tabular}

2008:

\begin{tabular}{cc}
$3.200,00$ & $\begin{array}{c}281 \text { Amortización acumulada } \\
\text { del inmovilizado material }\end{array}$ \\
\hline
\end{tabular}

La amortización correspondiente al ejercicio 2008 se calculará ya de acuerdo con el nuevo criterio contable:

$$
\frac{16.000}{1+2+3+4} \times 3=4.800
$$

31-12-08:

$$
\begin{array}{cccc}
\cline { 2 - 3 } & \begin{array}{c}
681 \text { Amortización del } \\
\text { inmovilizado material }
\end{array} & \text { a } \begin{array}{c}
281 \text { Amortización acumulada } \\
\text { del inmovilizado material }
\end{array}
\end{array}
$$

El estado de cambios en el patrimonio neto correspondiente al ejercicio terminado 2008 debería incluir un ajuste por el cambio anterior (por simplicidad se ha supuesto que no se producen variaciones en el patrimonio neto a lo largo del año 2007): 


\begin{tabular}{|l|c|c|c|c|}
\hline & Capital & $\begin{array}{c}\text { Prima de } \\
\text { emisión }\end{array}$ & Reservas & $\ldots$ \\
\hline A. Saldo, final del año 2006 & $\mathbf{x x x}$ & $\mathbf{x x x}$ & $\mathbf{1 0 . 0 0 0}$ & \\
\hline I. Ajustes por cambio de criterio 2006 y anteriores & & & +2.400 & \\
\hline II. Ajustes por errores 2006 y anteriores & & & & \\
\hline B. Saldo ajustado, inicio del año 2007 & $\mathbf{x x x}$ & $\mathbf{x x x}$ & $\mathbf{1 2 . 4 0 0}$ & \\
\hline$\ldots$ & & & & \\
\hline C. Saldo, final del año 2007 & $\mathbf{x x x}$ & $\mathbf{x x x}$ & $\mathbf{1 2 . 4 0 0}$ & \\
\hline I. Ajustes por cambio de criterio 2007 & & & +800 & \\
\hline II. Ajustes por errores 2007 & & & & \\
\hline D. Saldo ajustado, inicio del año 2008 & $\mathbf{x x x}$ & $\mathbf{x x x}$ & $\mathbf{1 3 . 2 0 0}$ & \\
\hline
\end{tabular}

\section{LOS CAMBIOS EN LAS ESTIMACIONES CONTABLES}

\subsection{Cambios en estimaciones contables: Razón de ser}

Debido a la incertidumbre que rodea a la actividad empresarial, la realización de estimaciones resulta inherente al propio proceso contable y constituye una parte fundamental de la elaboración de la información financiera. Algunas de las fuentes más habituales de estimaciones son:

- Determinación de la vida útil y del valor residual de los elementos de inmovilizado.

- Estimación del riesgo de insolvencias (deterioros de valor de créditos por operaciones comerciales).

- Estimación del riesgo de devoluciones por parte de los clientes.

La estimación tiene en cuenta todos los hechos y circunstancias existentes en el momento de su realización, pero cambia a medida que esos hechos o circunstancias se modifican. Por tanto, si de la obtención de información adicional, de una mayor experiencia o del conocimiento de nuevos contables se deriva la necesidad de realizar un cambio en las estimaciones, no se modificarán los resultados de ejercicios previos, pues éstos se realizaron de forma coherente con la información disponible en ese momento, sino que se contabilizan directamente como resultados del ejercicio actual y de los ejercicios futuros afectados, si existieran (contabilización prospectiva).

De acuerdo con la Norma de Registro y Valoración $n^{\circ} 22$, el efecto derivado del cambio en las estimaciones se imputará, según la 
naturaleza de la operación de que se trate, como ingreso o gasto en la cuenta de pérdidas y ganancias del ejercicio actual y de los ejercicios futuros afectados, o directamente al patrimonio neto, cuando proceda. Asimismo, debe incluirse información en la memoria sobre la naturaleza e importe de cualquier cambio en una estimación contable que haya producido efectos significativos en el ejercicio actual, o que vaya a producirlos en los siguientes.

El PGC de 1990 no especificaba expresamente el tratamiento contable de los cambios en las estimaciones, dando a entender así su imputación como resultados ordinarios o extraordinarios del ejercicio, según su naturaleza. Posteriormente, el ICAC sí ha recogido a lo largo de sus resoluciones un tratamiento similar al propuesto por el NPGC.

\section{Ejemplo n ${ }^{0}$ 10.-}

Registrar adecuadamente, de acuerdo con las Normas de Registro y Valoración del NPGC, los siguientes hechos contables.

Caso 1.- La sociedad "Medias y Ligas, S.A." (MELISA) adquirió el 1-6-05 una máquina por importe de 100.000€, que se decide amortizar de forma lineal, estimando su vida útil en 10 años y un valor residual al final de la misma de 6.000€. A finales de 2008, cuando está pendiente de ser contabilizada la dotación anual por la amortización de la máquina, se acuerda que deberá ser sustituida a comienzos del año 2012 para poner en funcionamiento una nueva con mayor capacidad productiva. El valor que se estima podrá obtenerse por la venta de la máquina antigua será de $8.400 €$.

\section{Solución.-}

El cambio en la estimación inicial de la vida útil debe aplicarse de forma prospectiva, distribuyendo el valor amortizable pendiente entre el número de años que restan de vida útil. A efectos contables, se considera que el cambio en la estimación tiene lugar a comienzos del ejercicio actual (2008):

1) Amortización Acumulada hasta el cambio (del 1-6-05 al 1-1-08):

$$
\frac{(100.000-6.000)}{10} \times\left(2+\frac{7}{12}\right)=24.283 €
$$

2) Valor amortizable pendiente: $100.000-24.283-8.400=67.317 €$.

Vida útil pendiente: 4 años.

Nueva cuota de amortización anual: $67.317 / 4=16.829,17 €$

31-12-08:

\begin{tabular}{ccc} 
& $\begin{array}{c}681 \text { Amortización del } \\
\text { inmovilizado material }\end{array}$ & a $\begin{array}{c}281 \text { Amortización acumulada } \\
\text { del inmovilizado material }\end{array}$ \\
\hline
\end{tabular}


Caso 2.- La empresa eléctrica "HUMOSA" explota una central de energía térmica, que fue construida en enero de 2008, con un coste de 10.000.000€. El importe de los costes de desmantelamiento de la central térmica al final de sus 25 años de vida útil, y de restauración del lugar por los daños medioambientales causados en su construcción, se estima en 1.500.000€ que se abonarán a finales del año 2032. No obstante, a finales del año 2009 la empresa realiza un nuevo estudio de los costes de desmantelamiento y estima que éstos ascenderán a 1.800.000€. Al cabo de 25 años, el coste final de desmantelamiento asciende a 1.750.000€. Por simplicidad se considera que el tipo de descuento adecuado es del 3,5\% durante todos los años de vida útil.

\section{Solución.-}

El desmantelamiento futuro de la central térmica genera una provisión por desmantelamiento, retiro o rehabilitación del inmovilizado a largo plazo que deberá ser objeto de actualización anual. De forma simplificada, a continuación se recogen los primeros y últimos años del cuadro de actualización de la provisión, así como el cambio de estimación realizado en el ejercicio 2009.

\begin{tabular}{|c|c|c|c|c|}
\hline & Valor actual 1-1 & \multicolumn{2}{|c|}{ Valor actual 31-12 } & $\begin{array}{c}\text { Ajuste } \\
\text { provisión }\end{array}$ \\
\hline \multirow{2}{*}{2008} & $V A_{\text {Enero-08 }}=\frac{1.500 .000}{(1+0,035)^{25}}=634.720,48$ & & & $\begin{array}{l}\text { Dotación } \\
\text { provisión: } \\
634.720,48\end{array}$ \\
\hline & $634.720,48$ & $V A_{08}=\frac{1.500 .000}{(1+0,035)^{24}}$ & $656.935,70$ & $\begin{array}{c}22.215,22 \\
\text { (Difer. financiera) }\end{array}$ \\
\hline \multirow[b]{2}{*}{2009} & $656.935,70$ & $V A_{09}=\frac{1.500 .000}{(1+0,035)^{23}}$ & $679.928,45$ & $\begin{array}{c}22.992,75 \\
\text { (Difer. financiera) }\end{array}$ \\
\hline & & $V A_{09}=\frac{1.800 .000}{(1+0,035)^{23}}$ & $815.914,14$ & $\begin{array}{c}135.985,69 \\
\text { (Cambio } \\
\text { estimación: } \\
\text { dotación) }\end{array}$ \\
\hline 2010 & $815.914,14$ & $V A_{10}=\frac{1.800 .000}{(1+0,035)^{22}}$ & $844.471,14$ & $\begin{array}{c}28.557,00 \\
\text { (Difer. financiera) }\end{array}$ \\
\hline 2011 & $844.471,14$ & $V A_{11}=\frac{1.800 .000}{(1+0,035)^{21}}$ & $874.027,63$ & $\begin{array}{c}29.556,49 \\
\text { (Difer. financiera) }\end{array}$ \\
\hline 2012 & $874.027,63$ & $V A_{12}=\frac{1.800 .000}{(1+0,035)^{20}}$ & $904.618,59$ & $\begin{array}{c}30.590,97 \\
\text { (Difer. financiera) }\end{array}$ \\
\hline$\ldots$ & $\ldots$ & $\ldots$ & $\ldots$ & $\ldots$ \\
\hline 2031 & $1.680 .319,26$ & $V A_{31}=\frac{1.800 .000}{(1+0,035)^{1}}$ & $1.739 .130,43$ & $\begin{array}{c}58.811,17 \\
\text { (Difer. financiera) }\end{array}$ \\
\hline 2032 & $1.739 .130,43$ & $V A_{32}=\frac{1.800 .000}{(1+0,035)^{0}}$ & $1.800 .000,00$ & $\begin{array}{c}60.869,57 \\
\text { (Difer. financiera) }\end{array}$ \\
\hline
\end{tabular}

1-08:

\begin{tabular}{|c|c|c|c|}
\hline $10.000 .000,00$ & $\begin{array}{l}2110 \text { Construcciones (central } \\
\text { térmica) }\end{array}$ & $\begin{array}{l}\text { a } 173 \text { Proveedores de inmovilizado } \\
\text { a } 1 / \mathrm{p}\end{array}$ & $10.000 .000,00$ \\
\hline $634.720,48$ & $\begin{array}{l}2111 \text { Construcciones } \\
\text { (desmantelamiento) }\end{array}$ & $\begin{array}{c}\text { a } 143 \text { Provisión por desm., retiro o } \\
\text { rehabilitac. del inmovilizado }\end{array}$ & $634.720,48$ \\
\hline
\end{tabular}


31-12-08:

\begin{tabular}{ll}
\cline { 2 - 2 } $425.388,82$ & $\begin{array}{c}\text { 681 Amortización del } \\
\text { inmovilizado material } \\
(10.000 .000 / 25)+\end{array}$ \\
$22.215,22$ & $\begin{array}{c}(634.720,48 / 25) \\
\text { 660 Gastos financieros por } \\
\text { actualización de provisiones }\end{array}$ \\
\hline
\end{tabular}

a 28110 Amortización acumulada construcción (central) $400.000,00$ a 28111 Amortización acumulada construcción (desmantelamiento)

31-12-09:

\begin{tabular}{cc}
$425.388,82$ & $\begin{array}{c}681 \text { Amortización del } \\
\text { inmovilizado material } \\
(10.000 .000 / 25)+\end{array}$ \\
$22.992,75$ & $\begin{array}{c}(634.720,48 / 25) \\
\text { 660 Gastos financieros por } \\
\text { actualización de provisiones }\end{array}$ \\
\hline
\end{tabular}

a 28110 Amortización acumulada construcción (central)

a 28111 Amortización acumulada construcción (desmantelamiento)

a 143 Provisión por desm., retiro o rehabilitac. del inmovilizado

$22.992,75$

Por el cambio en la estimación a finales del año 2009:

31-12-09:

\begin{aligned} & $135.985,69 \begin{array}{r}2111 \text { Construcciones } \\ (\text { desmantelamiento })\end{array} \\ &$\hline\end{aligned}

a 143 Provisión por desm., retiro o rehabilitac. del inmovilizado

$135.985,69$

Para calcular la amortización del año 2010 y siguientes respecto a los costes de desmantelamiento, debe tenerse en cuenta el nuevo valor amortizable, dividiendo el importe pendiente entre el número de años que restan de vida útil, como sigue:

1) Amortización Acumulada hasta el año 2010 (del 1-1-08 al 31-12-09):

$$
\frac{634.720,48}{25} \times 2=50.777,64 €
$$

2) Valor amortizable pendiente: $(634.720,48+135.985,69)-50.777,64=719.928,53 €$

Vida útil pendiente: $25-2=23$ años

Nueva cuota de amortización anual: 719.928,53 / $23=31.301,24 €$

31-12-10:

\begin{tabular}{cc} 
431.301,24 & $\begin{array}{c}\text { 681 Amortización del } \\
\text { inmovilizado material } \\
(10.000 .000 / 25)+\end{array}$ \\
& $(719.928,53 / 23)$ \\
\cline { 2 - 2 } $28.557,00$ & $\begin{array}{c}660 \text { Gastos financieros por } \\
\text { actualización de provisiones }\end{array}$ \\
\hline
\end{tabular}

a 28110 Amortización acumulada construcción (central)

$400.000,00$

a 28111 Amortización acumulada construcción (desmantelamiento)

a 143 Provisión por desm., retiro o rehabilitac. del inmovilizado

$31.301,24$

$28.557,00$

31-12-11:
28110 Amortización acumulada construcción (central) $400.000,00$ $(10.000 .000 / 25)+$ $(719.928,53 / 23)$ a 28111 Amortización acumulada construcción (desmantelamiento) 


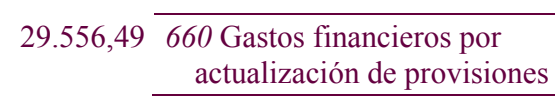

$400.000,00$

$31.301,24$

$30.590,97$

(...) Finalmente, para los dos últimos años de vida útil de la central térmica:

31-12-31:

\begin{tabular}{|c|c|}
\hline $431.301,24$ & $\begin{array}{l}\text { 681 Amortización del } \\
\text { inmovilizado material } \\
(10.000 .000 / 25)+ \\
(719.928,53 / 23)\end{array}$ \\
\hline $58.811,17$ & $\begin{array}{l}660 \text { Gastos financieros por } \\
\text { actualización de provisiones }\end{array}$ \\
\hline
\end{tabular}

28110 Amortización acumulada construcción (central)

$400.000,00$

a 28111 Amortización acumulada construcción (desmantelamiento)

a 143 Provisión por desm., retiro o rehabilitac. del inmovilizado

$58.811,17$

\section{1-12-32:}

$\begin{array}{ll}\text { 431.301,24 } & \begin{array}{c}\text { 681 Amortización del } \\ \text { inmovilizado material } \\ (10.000 .000 / 25)+\end{array} \\ & \begin{array}{l}(719.928,53 / 23) \\ 60.869,57\end{array} \\ \begin{array}{c}660 \text { Gastos financieros por } \\ \text { actualización de provisiones }\end{array}\end{array}$
28110 Amortización acumulada construcción (central) 28111 Amortización acumulada construcción (desmantelamiento) $400.000,00$

Si se calcula el libro mayor de las cuentas de "amortización acumulada de construcciones" y "provisión por desmantelamiento" a fecha 31-12-32 pueden observarse los siguientes saldos:

\section{Amortización acum.} construcción (central)

10.000 .000

28110 Amortización acum. construcción (rehabilitación)

$$
\begin{array}{r}
50.777,64 \\
719.928,53 \\
\\
\text { Sa: } 770.706,17
\end{array}
$$

143 Provisión por desmant., retiro o rehab. inmovilizado

$634.720,48$

$1.029 .293,83$

$135.985,69$

Sa: $1.800 .000,00$

En enero de 2033 se desmantela la central, ascendiendo el coste final a 1.750.000€:

$$
\text { 31-12-33: }
$$

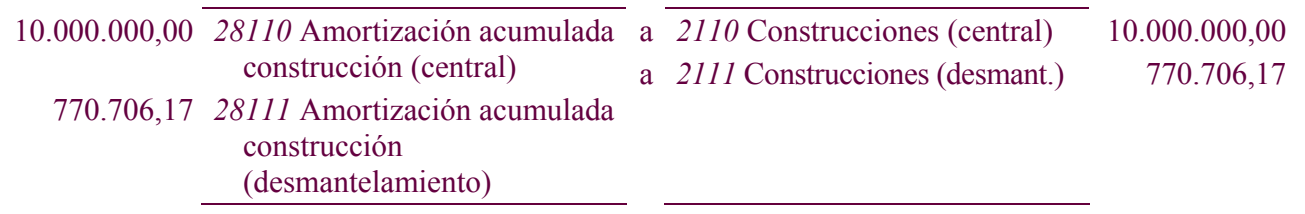




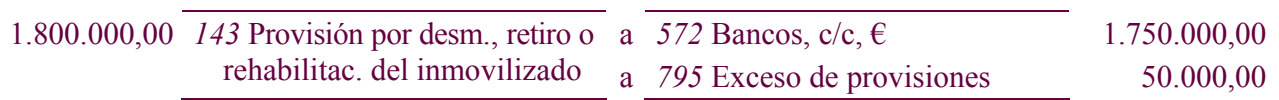

\section{LA CORRECCIÓN DE ERRORES CONTABLES}

\subsection{Errores: Razón de ser}

Los errores contables hacen referencia a omisiones o inexactitudes en las cuentas anuales como resultado de una mala aplicación de las políticas contables o de una mala interpretación de los hechos y circunstancias que existen en la fecha en que se presentan los estados financieros.

El principio de importancia relativa recogido en el Marco Conceptual del NPGC permite la no aplicación estricta de algunos de los principios y criterios contables, siempre que su repercusión cuantitativa o cualitativa sea escasamente significativa y no altere la expresión de la imagen fiel de las Cuentas Anuales. Por tanto, la corrección de errores regulada en la Norma de Registro y Valoración $n^{\circ} 22$ "Cambios en criterios contables, errores y estimaciones contables" hace referencia exclusivamente a errores materiales que afectan de forma significativa a la relevancia y fiabilidad de los estados financieros.

\subsection{Reconocimiento y registro contable}

A diferencia del PGC de 1990, que no regulaba la corrección de errores, el NPGC establece que los errores cometidos deben corregirse tan pronto como sean detectados. La corrección dependerá del momento en que se detecte el error (Norma de Registro y Valoración $n^{\circ} 22$ ):

1. Los errores cometidos en el ejercicio corriente se corrigen antes de que los estados financieros sean formulados, efectuando los ajustes oportunos con cargo y abono a las correspondientes cuentas del balance y de resultados del ejercicio actual.

2. Para los errores imputables a ejercicios anteriores son de aplicación las mismas reglas que para los cambios en criterios contables, imputándose directamente en el patrimonio neto, en concreto, en una partida de reservas. También debe reexpresarse la información comparativa que corresponda al ejercicio o ejercicios en que se originó el error, a menos que no sea posible realizarlo; en este 
último caso, se ajustará únicamente la información contable del ejercicio o ejercicios para los que se disponga de dicha información. Respecto al estado de cambios en el patrimonio neto, debe ajustarse el saldo inicial del ejercicio o ejercicios afectados por el error.

En la memoria corresponde incluir información sobre la naturaleza del error significativo, la cuantía de la corrección imputada al ejercicio actual y, en su caso, a cada uno de los precedentes para los que se presente información. Los ajustes efectuados no suponen, necesariamente, la modificación de los estados financieros aprobados y depositados en los registros legales correspondientes.

\section{Ejemplo n ${ }^{0}$ 11.-}

Registrar adecuadamente, de acuerdo con las Normas de Registro y Valoración del NPGC, los siguientes hechos contables.

Caso 1.- La sociedad "Medias y Ligas, S.A." (MELISA) adquirió el 1-6-05 una máquina por importe de 100.000€, que se decide amortizar de forma lineal, estimando su vida útil en 10 años y un valor residual al final de la misma de 6.000€. A finales de 2008, cuando está pendiente de ser contabilizada la dotación anual por la amortización de la máquina, se observa que la vida útil está incorrectamente calculada, siendo realmente de 8 años. Se mantiene el valor residual inicial.

\section{Solución.-}

En este caso la sociedad MELISA ha cometido un error al estimar la vida útil de la maquinaria, que debe ser corregido con efectos retroactivos.

\begin{tabular}{|c|c|c|c|}
\hline & $\begin{array}{c}\text { Cuota de amortización vida } \\
\text { útil correcta }(8 \text { años })\end{array}$ & $\begin{array}{c}\text { Cuota de amortización vida } \\
\text { útil errónea }(10 \text { años })\end{array}$ & $\begin{array}{c}\text { Diferencia respecto a la } \\
\text { contabilización inicial }\end{array}$ \\
\hline 2005 & $94.000 / 8 \times 7 / 12=6.854,17$ & $94.000 / 10 \times 7 / 12=5.483,33$ & $+1.370,83$ \\
\hline 2006 & $94.000 / 8=11.750,00$ & $94.000 / 10=9.400,00$ & $+2.350,00$ \\
\hline 2007 & $94.000 / 8=11.750,00$ & $94.000 / 10=9.400,00$ & $+2.350,00$ \\
\hline Total & $30.354,17$ & $24.283,33$ & $+6.070,83$ \\
\hline
\end{tabular}

2008:

\begin{tabular}{ccc}
$6.070,83$ & a $\begin{array}{c}281 \text { Amortización acumulada } \\
\text { del inmovilizado material }\end{array}$ \\
\hline
\end{tabular}

La amortización correspondiente al ejercicio 2008 se calcula ya correctamente:

31-12-08 


\begin{tabular}{|c|c|c|}
\hline $11.750,00$ & $\begin{array}{l}681 \text { Amortización del } \\
\text { inmovilizado material }\end{array}$ & $\begin{array}{c}\text { a } 281 \text { Amortización acumulada } \\
\text { del inmovilizado material }\end{array}$ \\
\hline
\end{tabular}

El estado de cambios en el patrimonio neto correspondiente al ejercicio terminado 2008 debe ser objeto de ajuste para incluir la corrección del error:

\begin{tabular}{|l|c|c|c|c|}
\hline & Capital & $\begin{array}{c}\text { Prima de } \\
\text { emisión }\end{array}$ & Reservas & $\ldots$ \\
\hline C. Saldo, final del año 2008 & $\mathbf{x x x}$ & $\mathbf{x x x}$ & $\mathbf{1 0 . 0 0 0 , 0 0}$ & \\
\hline I. Ajustes por cambio de criterio 2008 & & & & \\
\hline II. Ajustes por errores 2008 & & & $-6.070,86$ & \\
\hline D. Saldo ajustado, inicio del año 2009 & $\mathbf{x x x}$ & $\mathbf{x x x}$ & $\mathbf{3 . 9 2 9 , 1 4}$ & \\
\hline
\end{tabular}

Caso 2.- La empresa "LAGUNO, S.A." comete al cierre del ejercicio 2008 un error en la realización de su inventario, al no incluir como existencias una partida de mercaderías cuyo coste de adquisición asciende a 50.000€. Realizar las anotaciones contables necesarias para corregir el error suponiendo que éste se descubre antes del cierre de la Contabilidad del año 2008.

\section{Solución.-}

Si el error se descubre durante el mismo ejercicio en que se cometió, su corrección es inmediata, realizándose el cargo y abono de las cuentas cuyo saldo es incorrecto ("300. Mercaderías" y "610. Variación de existencias de mercaderías").

31-12-08:

$\begin{array}{llll}50.000,00 & 300 \text { Mercaderías } & \text { a } \begin{array}{cc}610 \text { Variación de existencias de } \\ \text { mercaderías }\end{array} & 50.000,00\end{array}$

Caso 3.- Respecto al error cometido por la empresa LAGUNOSA durante el año 2008, supóngase que éste se descubre a lo largo del ejercicio 2009.

\section{Solución.-}

Si el error se descubre al año siguiente de su comisión, los ajustes correspondientes a los gastos e ingresos afectados deben realizarse con cargo o abono a la cuenta "113. Reservas voluntarias". 2009:

\begin{tabular}{|c|c|c|}
\hline $50.000,00$ & 300 Mercaderías & a 113 Reservas voluntarias \\
\hline
\end{tabular}

El estado de cambios en el patrimonio neto correspondiente al ejercicio terminado 2009 debe incluir un ajuste por la corrección del error:

\begin{tabular}{|l|c|c|c|c|}
\hline & Capital & $\begin{array}{c}\text { Prima de } \\
\text { emisión }\end{array}$ & Reservas & $\ldots$ \\
\hline C. Saldo, final del año 2008 & $\mathbf{x x x}$ & $\mathbf{x x x}$ & $\mathbf{1 0 0 . 0 0 0}$ & \\
\hline I. Ajustes por cambio de criterio 2008 & & & & \\
\hline II. Ajustes por errores 2008 & & & +50.000 & \\
\hline D. Saldo ajustado, inicio del año 2009 & $\mathbf{x x x}$ & $\mathbf{x x x}$ & $\mathbf{1 5 0 . 0 0 0}$ & \\
\hline
\end{tabular}


Caso 4.- Respecto al error cometido por la empresa LAGUNOSA durante el año 2008, supóngase que éste se descubre a lo largo del ejercicio 2010.

Solución.-

En este caso, existen dos errores acumulados que deben corregirse: (1) el resultado del año 2008 que se encuentra infravalorado en 50.000€ al ser las existencias finales reales superiores a las contables; y (2) el resultado del año 2009 que se encuentra sobrevalorado en $50.000 €$ al ser las existencias iniciales superiores a las reales en $50.000 €$.

Aunque no es habitual, el error cometido en 2008 se compensa con el cometido en 2009, por lo que no procede ajuste contable.

El estado de cambios en el patrimonio neto correspondiente al ejercicio terminado 2010 debería incluir los ajustes correspondientes a ambos errores (por simplicidad se ha supuesto que no se producen variaciones en el patrimonio neto a lo largo del año 2009):

\begin{tabular}{|l|c|c|c|c|}
\hline & Capital & $\begin{array}{c}\text { Prima de } \\
\text { emisión }\end{array}$ & Reservas & $\ldots$ \\
\hline A. Saldo, final del año 2008 & $\mathbf{x x x}$ & $\mathbf{x x x}$ & $\mathbf{1 0 0 . 0 0 0}$ & \\
\hline I. Ajustes por cambio de criterio 2008 y anteriores & & & & \\
\hline II. Ajustes por errores 2008 y anteriores & & & +50.000 & \\
\hline B. Saldo ajustado, inicio del año 2009 & $\mathbf{x x x}$ & $\mathbf{x x x}$ & $\mathbf{1 5 0 . 0 0 0}$ & \\
\hline .. & & & & \\
\hline C. Saldo, final del año 2009 & $\mathbf{x x x}$ & $\mathbf{x x x}$ & $\mathbf{1 5 0 . 0 0 0}$ & \\
\hline I. Ajustes por cambio de criterio 2009 & & & & \\
\hline II. Ajustes por errores 2009 & & & -50.000 & \\
\hline D. Saldo ajustado, inicio del año 2010 & $\mathbf{x x x}$ & $\mathbf{x x x}$ & $\mathbf{1 0 0 . 0 0 0}$ & \\
\hline
\end{tabular}

En algunos casos puede ser difícil determinar si un hecho contable concreto representa un cambio en criterios contables, un cambio en las estimaciones, o un error que debe ser corregido. Aunque el NPGC no regula expresamente estas situaciones, la NIC 8 aprobada por la Comisión Europea establece que tales hechos contables se tratarán en todo caso de forma prospectiva (como un cambio en las estimaciones), revelando en la memoria la información correspondiente.

\section{LOS HECHOS POSTERIORES AL CIERRE DEL EJERCICIO}

\subsection{Hechos posteriores al cierre: Razón de ser}

El NPGC incluye como una de principales novedades la determinación de cuándo una empresa debe proceder a ajustar sus estados 
financieros como consecuencia de hechos posteriores a la fecha del balance, y la información que debe proporcionar respecto a los mismos.

La Norma de Registro y Valoración $\mathrm{n}^{\circ} 23$ del NPGC se destina exclusivamente a regular los hechos posteriores al cierre del ejercicio, definidos como aquellos hechos que tienen trascendencia contable o informativa para los usuarios de los estados financieros, y que suceden después del cierre de un ejercicio pero en una fecha previa a su formulación ${ }^{11}$ (Figura 2).

Figura 2. Incidencia de los hechos posteriores al cierre

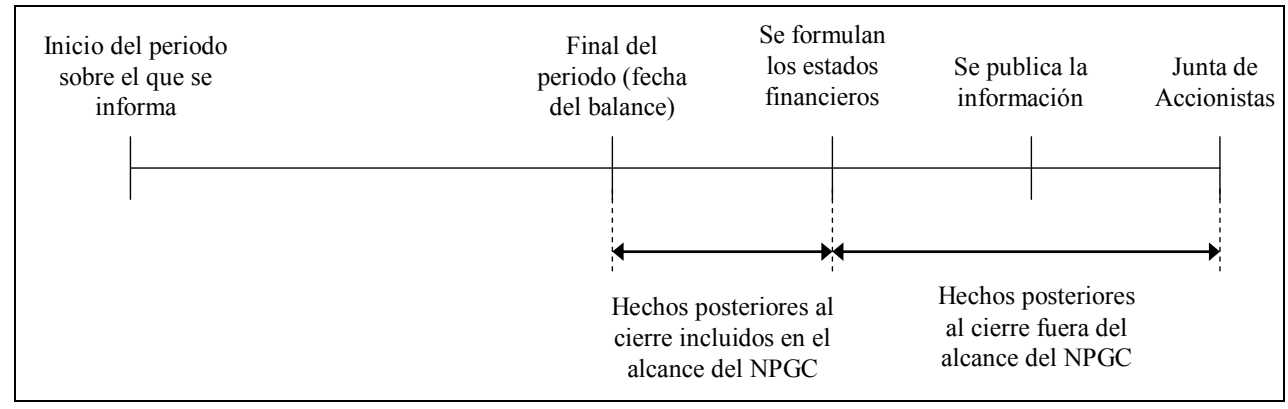

Fuente: Elaboración propia.

A efectos contables, pueden distinguirse dos tipos de hechos posteriores al cierre:

1) Hechos que ponen de manifiesto condiciones que no existían al cierre del ejercicio.

2) Hechos que ponen de manifiesto condiciones que ya existían al cierre del ejercicio.

Ante esta clasificación, el problema reside en determinar qué se entiende por una condición que ya existía a la fecha del balance, y en qué momento surge la circunstancia que puede llegar a influir en la toma de decisiones de los usuarios de los estados financieros. La

11 De acuerdo con la legislación española, las cuentas anuales deberán ser formuladas por el Consejo de Administración en un plazo máximo de 3 meses a contar desde la fecha de cierre. Según la NIC 10, la formulación de los estados coincide con la autorización para su divulgación. 
clasificación exige así, por parte del gestor, el conocimiento y evaluación de los hechos posteriores y de las circunstancias que los produjeron.

\subsection{Reconocimiento y registro contable}

Los hechos posteriores al cierre del ejercicio que pongan de manifiesto condiciones que no existían al cierre del mismo no implican ajustes en las cuentas anuales ya formuladas, pues son el resultado de circunstancias surgidas después de la fecha de balance. Como excepción, si los hechos son de tal importancia que, si no se facilitara información al respecto podría distorsionarse la capacidad de evaluación de los usuarios de las cuentas anuales, debe incluirse información en la memoria respecto a su naturaleza y su efecto estimado sobre los estados financieros, o incluir una aclaración expresando que no es posible llegar a tal estimación.

Los hechos posteriores que pongan de manifiesto condiciones que ya existían al cierre del ejercicio, deberán tenerse en cuenta para la formulación de las cuentas anuales ${ }^{12}$. El ajuste en las cuentas anuales se hará necesario en función de su importancia relativa. En los estados financieros debe revelarse información acerca de la fecha de su formulación y quién es el responsable de la misma, para informar a los usuarios de la fecha hasta la que los hechos han sido considerados.

En cualquier caso, todo hecho posterior al cierre que pueda afectar a la aplicación del principio de empresa en funcionamiento, tales como la intención de los gestores de liquidar la empresa o cesar en su actividad, debe tenerse en cuenta en la formulación de las cuentas anuales. La NIC 10 va más allá de la regulación del NPGC, y exige expresamente a la empresa que no prepare sus estados financieros bajo la hipótesis de empresa en funcionamiento si los hechos posteriores a la fecha del balance indican que tal hipótesis no resulta apropiada.

El PGC de 1990 apenas regulaba los hechos posteriores al cierre, indicando únicamente la conveniencia de informar en la memoria sin necesidad de ajustar las Cuentas Anuales. Por su parte, la Norma Técnica de Auditoría sobre hechos posteriores publicada por el ICAC en

12 El borrador del NPGC contemplaba incluso la posibilidad de modificar los estados financieros entre la fecha de su formulación y la fecha de su aprobación, finalmente las Cuentas Anuales sólo se reformularán de forma muy excepcional, cuando los hechos posteriores al cierre sean de máxima relevancia y afecten de forma muy significativa a la imagen fiel. 
2003 ya incluía este tipo de información, si bien incluyéndola en la nota 19 de la memoria (versión normal).

La Tabla 3 resume algunos ejemplos de hechos posteriores al cierre del ejercicio que dan lugar o no a ajustes de las cuentas anuales, de acuerdo con la NIC 10 que sirve de guía al NPGC.

Tabla 3. Ejemplos de hechos posteriores al cierre del ejercicio

\begin{tabular}{|c|l|l|}
\hline \multirow{4}{*}{$\begin{array}{c}\text { Hechos posteriores } \\
\text { que dan lugar a } \\
\text { ajustes }\end{array}$} & $\begin{array}{l}\text { Quiebra de un cliente, ocurrida } \\
\text { después de la fecha del Balance }\end{array}$ & $\begin{array}{l}\text { Suele confirmar que al cierre ya existía } \\
\text { una pérdida sobre la cuenta comercial a } \\
\text { cobrar, por lo que la empresa debería } \\
\text { ajustar el valor en libros de esa cuenta }\end{array}$ \\
\cline { 2 - 3 } & $\begin{array}{l}\text { Resolución de un litigio judicial } \\
\text { después de la fecha del Balance }\end{array}$ & $\begin{array}{l}\text { Obliga a realizar un ajuste en el importe } \\
\text { de la provisión previamente reconocida, o } \\
\text { a registrar una nueva provisión }\end{array}$ \\
\cline { 2 - 3 } $\begin{array}{l}\text { Descubrimiento de fraudes o } \\
\text { errores que pongan de manifiesto } \\
\text { que los estados formulados al } \\
\text { cierre eran incorrectos }\end{array}$ & $\begin{array}{l}\text { Deberá llevarse a cabo la corrección del } \\
\text { error correspondiente }\end{array}$ \\
\hline \multirow{4}{*}{$\begin{array}{c}\text { Hechos posteriores no dan lugar a } \\
\text { ajustes }\end{array}$} & $\begin{array}{l}\text { Reducción en el valor de mercado de las inversiones financieras, ocurrida } \\
\text { entre la fecha de Balance y la fecha en que se formulan los estados } \\
\text { financieros }\end{array}$ \\
\cline { 2 - 3 } & \begin{tabular}{l} 
Compra significativa de activos, posterior al cierre \\
\cline { 2 - 3 }
\end{tabular} & $\begin{array}{l}\text { Expropiación, posterior al cierre, de un número o importe significativo de } \\
\text { activos por parte de la Administración Pública }\end{array}$ \\
\cline { 2 - 3 } & \multicolumn{2}{|l|}{ Destrucción de inventarios por un siniestro posterior al cierre } \\
\cline { 2 - 3 } & Dividendos propuestos para repartir a los accionistas ${ }^{13}$ \\
\hline
\end{tabular}

Fuente: Elaboración propia a partir de Sierra Capel y Sierra Capel (2004).

\section{Ejemplo $n^{0}$ 12.-}

La empresa "Beta" dedicada a la producción y venta al por mayor de vinos y licores, dispone de la siguiente información adicional, conocida entre la fecha de cierre del ejercicio y la fecha de formulación de las cuentas anuales del ejercicio:

Caso 1.- Durante el año 2008, la empresa realizó el recurso de una multa de estacionamiento, por importe de 500€, impuesta por el Ayuntamiento de León, habiendo contabilizado la correspondiente provisión dado que existen escasas garantías que el recurso prospere. El día 5-1-09 se recibe por correo la notificación de la resolución final (emitida el 30-12-08), en la que se ratifica la sanción.

13 Debe incluirse información en la memoria sobre los dividendos que hayan sido propuestos o declarados después de la fecha del balance, pero antes de que se hayan formulado los estados financieros (NIC 10.12). 


\section{Solución.-}

Se trata de un hecho contable que pone de manifiesto condiciones que ya existían al cierre del ejercicio, pero que la empresa conoce en un momento posterior. Será necesario ajustar las cuentas anuales de 2008, aplicando la provisión y reconociendo un pasivo cierto con la Hacienda Pública por importe de 500€. Por último, debe informarse en la memoria de este hecho contable.

Ajuste:

$$
\begin{gathered}
500,00 \begin{array}{l}
5292 \text { Provisión a c/p para otras a } \\
\text { responsabilidades }
\end{array} \\
\hline
\end{gathered}
$$

$4759 \mathrm{HP}$, acreedora por multas

Caso 2.- El día 7-1-09 la empresa descubre un error en la contabilización de una compra de mercaderías que tuvo lugar en diciembre de 2008. Si bien el importe correcto era de 17.000€, la operación fue registrada por importe de 170.000€ (se prescinde del IVA).

\section{Solución.-}

Se trata de un hecho contable que pone de manifiesto condiciones que ya existían al cierre del ejercicio, al tratarse de un error cometido a lo largo del ejercicio 2008. Será necesario ajustar las cuentas anuales de 2008, efectuando el correspondiente asiento de corrección de error e informando en la memoria:

\begin{tabular}{|c|c|c|c|}
\hline \multirow[t]{2}{*}{$153.000,00$} & \multirow{2}{*}{$\begin{array}{l}400 \text { Proveedores } \\
\qquad(170.000-17.000)\end{array}$} & $\mathrm{a}$ & 129 Pérdidas y ganancias \\
\hline & & $\mathrm{a}$ & $\begin{array}{l}4752 \mathrm{HP} \text {, acreedora por impuesto } \\
\text { sobre sociedades }(35 \%)\end{array}$ \\
\hline
\end{tabular}

Ajuste:

Caso 3.- El día 15-1-09 la empresa sufre un incendio, destruyendo la práctica totalidad del mobiliario de la empresa (precio de adquisición: 3.000€, amortización lineal en 5 años, fecha de adquisición 1-7-05).

\section{Solución.-}

Se trata de un hecho contable que pone de manifiesto condiciones que no existían al cierre del ejercicio, pero que son de importancia para la toma de decisiones por parte de los usuarios. No será necesario ajustar las cuentas anuales de 2008, pero sí es conveniente informar en la memoria del incendio ocurrido durante los primeros días de 2009, y su efecto sobre la continuidad de la empresa (en su caso).

Caso 4.- La empresa tiene adquiridas 100 acciones de Telemódica como inversión financiera temporal (valor nominal: 10€, cotización al cierre de 2008: 115\%). Se sabe que entre la fecha de cierre del ejercicio 2008 y la fecha de formulación de las cuentas anuales se han producido distintas variaciones en su valor razonable.

\section{Solución.-}

Se trata de un hecho contable que pone de manifiesto condiciones que no existían al cierre del ejercicio, pero que son de importancia para la toma de decisiones por parte de los usuarios. No será necesario ajustar las cuentas anuales de 2008, pero sí puede ser conveniente informar en la memoria si la caída en la cotización de las acciones es muy elevada. 


\section{CONCLUSIONES}

El NPGC ha modernizado la legislación contable española en materia de provisiones y retribuciones a largo plazo al personal, adaptándola al tratamiento recogido en las Normas Internacionales de Contabilidad adoptadas en la Unión Europea (NIC 19, NIC 37, NIIF 2). Al mismo tiempo, se ha tratado de mantener la tradición contable española en materia de normalización y registro, regulando estas operaciones mediante normas de valoración y registro de carácter obligatorio (N.R. y $\vee n^{\circ} 15$ y 16). Aunque los cambios son numerosos y afectan a distintos ámbitos de las Cuentas Anuales, las principales modificaciones proceden de la actualización de los saldos a largo plazo, el reconocimiento de nuevas provisiones (medioambientales, reestructuración, contratos onerosos, desmantelamiento del inmovilizado), y la modificación del tratamiento contable de las grandes reparaciones y los fondos de pensiones.

Asimismo, el NPGC regula de forma expresa los ajustes a efectuar en el caso de cambios en criterios contables y corrección de errores, que se aplicarán de forma retroactiva, modificando el patrimonio neto acumulado a través de las reservas disponibles de la empresa. Debido a su distinta naturaleza, los cambios en las estimaciones se aplicarán prospectivamente, afectando sólo al año actual y a ejercicios futuros, en su caso. Por su parte, los hechos posteriores al cierre que recojan circunstancias que ya existían al final del ejercicio, deberán ser incorporados a las cuentas anuales siempre que se conozcan antes de su formulación.

De esta forma, se profundiza en las normas de reconocimiento y valoración de estas operaciones, ampliando la información a suministrar en la memoria, con el objetivo de proporcionar mayor y mejor información a los usuarios de los estados financieros.

\section{BIBLIOGRAFÍA}

Alonso Pérez, A. y R. Pousa SOto (2007) Casos prácticos del Nuevo Plan General de Contabilidad: BOE de 20 de noviembre de 2007. Madrid: Centro de Estudios Financieros.

CAÑIBANO CALVO, L. y A. MORA ENGUídanos (2006) Las Normas Internacionales de Información Financiera: Análisis y Aplicación. Navarra: Thomson Civitas. 
Corona Romero, E.; J. Talavero Sanguino, F. García Martínez, J. Calvo GONZÁlEZ-VALINAS, A. MONZÓN SÁNCHEZ, J. VARELA COUCEIRO y R. LóPEZ GALINDO (2006) Aplicación de las Normas Internacionales de Contabilidad adoptadas por la Unión Europea (NICes). Bilbao: CISS Grupo Wolters Kluwer.

Esteban Cerdán, A. y J. Haro Pérez (2003) "NIC 8 Resultados del ejercicio: Errores y cambios de criterios contables", Partida Doble, $\mathrm{n}^{\circ} 150$, pp. 617.

Fernández Sotero, A. y I. Carazo González (2008) Plan General de Contabilidad. Comentarios y Casos Prácticos. Madrid: Centro de Estudios Financieros.

García MARTíneZ, F. (2007) "Las provisiones, contingencias, retribuciones al personal y pagos basados en instrumentos de patrimonio neto según el borrador del PGC", Técnica Contable, n 697, mayo.

García TabuYo, M. y J. HaRo Pérez (2007) "NIC 37: Provisiones, activos contingentes y pasivos contingentes", Partida Doble, $\mathrm{n}^{\circ} 184$, pp. 76-90.

LARRIBA DíAZ-ZORITA, A. (2007) "Provisiones y contingencias", Expansión, 21 de abril, pp. 30-31.

PULIDO, A. (2007) "Los cambios en criterios y en estimaciones", Expansión, 25 de abril, p. 40.

Sierra CaPel, F.J. y J.M. SierRa CaPel (2004) "Hechos posteriores al cierre del balance: la NIC 10", Partida Doble, n 153, pp. 6-17.

TORVISCO MANCHÓN, B. Y M.R. FLORES JIMENO (2008) "El nuevo PGC: provisiones, cambios en criterios contables, errores, estimaciones contables y hechos posteriores", Partida Doble, pp. 18-29.

\section{NORMATIVA REGULADORA}

INSTITUTO DE CONTABILIDAD Y AUDITORÍA DE CUENTAS (ICAC) (2007) [en línea]: "Normas Internacionales de Información Financiera aprobadas por la Unión Europea. Texto completo. NIC 8". Disponible en: http://www.icac.meh.es/reglanic.htm (fecha de consulta: 2-8-2008)

- (2007) [en línea]: "Normas Internacionales de Información Financiera aprobadas por la Unión Europea. Texto completo. NIC 10". Disponible 
en: http://www.icac.meh.es/reglanic.htm (fecha de consulta: 2-82008)

- (2007) [en línea]: "Normas Internacionales de Información Financiera aprobadas por la Unión Europea. Texto completo. SIC 8". Disponible en: http://www.icac.meh.es/reglanic.htm (fecha de consulta: 2-82008)

- (2007) [en línea]: "Normas Internacionales de Información Financiera aprobadas por la Unión Europea. Texto completo. SIC 18". Disponible en: http://www.icac.meh.es/reglanic.htm (fecha de consulta: 2-82008)

- (2007) [en línea]: "Normas Internacionales de Información Financiera aprobadas por la Unión Europea. Texto completo. NIC 37". Disponible en: http://www.icac.meh.es/reglanic.htm (fecha de consulta: 2-82008)

- (2007) [en línea]: "Normas Internacionales de Información Financiera aprobadas por la Unión Europea. Texto completo. NIC 19". Disponible en: http://www.icac.meh.es/reglanic.htm (fecha de consulta: 2-82008)

- (2007) [en línea]: "Normas Internacionales de Información Financiera aprobadas por la Unión Europea. Texto completo. NIIF 2". Disponible en: http://www.icac.meh.es/reglanic.htm (fecha de consulta: 2-82008)

REAL DeCRETO 1514/2007, de 16 de Noviembre, por el que se aprueba el Plan General de Contabilidad (BOE 20-11-2007). Disponible en: http: //www.icac.meh.es

REAL DECRETO 1515/2007, de 16 de Noviembre, por el que se aprueba el Plan General de Contabilidad para PYMEs (BOE 20-11-2007). Disponible en: http://www.icac.meh.es 